\title{
The leptolepid fish Cavenderichthys talbragarensis (Woodward, 1895) from the Talbragar Fish Bed (Late Jurassic) near Gulgong, New South Wales
}

\author{
L. B. Bean \\ Dept of Earth and Marine Sciences, The Australian National University, \\ Canberra, ACT 0200, Australia \\ e-mail: Lynne.Bean@ems.anu.edu.au
}

\begin{abstract}
Leptolepis" talbragarensis Woodward, 1895, is the most common fish species in the Talbragar Fish Bed near Gulgong, New South Wales. The genus Cavenderichthys Arratia, 1997, has this species as its type. The three species originally proposed by Woodward (1895) for "Leptolepis" are a single species. A detailed comparison of Cavenderichthys talbragarensis with members of the genus Leptolepis, and also with the Late Jurassic forms Tharsis dubius and Leptolepides sprattiformis, indicates that Cavenderichthys talbragarensis is most closely related to Late Jurassic members of the Family Leptolepididae. Analysis of zircons for geochronology showed that the sediment just below the richest fish layer has a youngest component of $151.55 \pm 4.27 \mathrm{Ma}$, corresponding to the Kimmeridgian Stage of the Late Jurassic. Thin sections of the upper prolific fish layer show preservation in tuffaceous sediments, indicating that the fish population was killed by ash falls of felsic tuff that filled the pond they inhabited.
\end{abstract}

\section{INTRODUCTION}

Fossil fishes were first discovered at Talbragar about $30 \mathrm{~km}$ northeast of Gulgong by Arthur Lowe of Wilbertree, NSW in 1889 (Woodward 1895). Later, many specimens were collected by Charles Cullen, the collector of fossils for the NSW Mines Department. This material is now in the Australian Museum, Sydney, and the NSW Department of Mineral Resources. Associated with the fishes is abundant plant material, first described by Walkom (1921), then re-examined and classified by White (1981). Some undescribed insect remains are also housed in the Australian Museum, Sydney.

Woodward (1895) described a representative selection of different fossil fishes that had been sent to London in 1890 . He considered that the assemblage was of Jurassic age, despite an original field assessment of the age as Triassic, made by $\mathrm{W}$. Anderson of the Geological Survey of NSW. The vast majority of the fishes in the material belong to Leptolepis talbragarensis Woodward, 1895, which was cited by Long (1991) as "the first appearance of the teleosteans in the Australian fossil record". Other fishes include one species of palaeoniscid, Coccolepis australis (Woodward, 1895), and the holosteans Archaeomaene tenui Woodward, 1895, Madariscus robustus Wade, 1941, Aphnelepis australis Woodward, 1895, Aetheolepis mirabilis Woodward, 1895, and Uarbryichthys latus Wade, 1941. Interest in Leptolepis talbragarensis is due largely to its early teleostean features. Nybelin (1974) suggested that $L$. talbragarensis should be excluded from the family Leptolepididae Agassiz, 1833-44. This was based partly on his own observations, but also on the work of Cavender (1970) who compared coregonines and other salmonids with some of the earliest known teleosts, including $L$. talbragarensis. Arratia (1997) erected a new genus, Cavenderichthys, with talbragarensis as the type species, on the basis of material from the Natural History Museum, London, the Field Museum of Natural History, Chicago, and the Swedish Museum of Natural History, but she did not have access to the vast amount of material available in Australia.

The Talbragar site has revealed the best-preserved Jurassic fish in Australia. The outcrop now is very poor, as so much material has been removed in the past and it is now in a paddock used for grazing. The age has been difficult to confirm because there is no control of stratigraphy as the relationship to surrounding rocks is unclear. Previously, no volcanic rocks had been identified to be dated, and palynology is impossible because of the highly oxidised nature of the rocks.

The assemblage of fossil fishes has been thought to indicate an Upper Jurassic age (Long 1991), but early workers suggested a Middle Jurassic age, for example Hind and Helby (1969) who suggested Early to Middle Jurassic based on palynology of the Purlawaugh Formation, within which the Fossil Fish Bed occurs. The site is interpreted as a mass kill site with a longitudinal extent of possibly 200 metres. The upper layer contains a high concentration of extremely well preserved fossil fish, while the layer below, probably less that one metre thick, has scattered fish throughout, 
indicating a lacustrine environment. Until now evidence for the cause of death has been sparse, although Percival (1979), and White (1981), have made suggestions.

The purpose of this paper is to reassess the description and classification of Cavenderichthys talbragarensis, and to discuss the environment of deposition, the age of the fossil bed, and the nature of preservation. To do this the type material in the Australian Museum, as well as about 250 other specimens from the Australian Museum, the N.S.W. Geological Survey and the Australian National University have been examined. The sediment has been studied in thin section, as has its geochemistry, and plant content. Zircon dating was carried out using the SHRIMP method.

\section{GEOLOGY}

The Talbragar Fossil Fish Bed is the informal name given by Dulhunty and Eadie (1969) to the outcrop found on the northeastern side of Farrs Hill, about $5 \mathrm{~km}$ south of the Talbragar River. The location is GR 753090 6437910, Dubbo 1:250 000 Geological Sheet (Pogson and Cameron 1999). The site is now a geological reserve administered by the National Parks and Wildlife Service, Mudgee Office. The strike is generally north-south, and the dip of adjacent beds is about $10^{\circ}$ west. The Fish Bed is thin, forming part of a non-marine sequence. Just below the fossil bed are layers that contain tuffaceous sections. Unweathered samples are grey, very fine grained, and contain angular fragments of minerals such as quartz, some of which is detrital and some of which appears to be igneous in origin. There is no evidence of sedimentary flow structure.

Stratigraphically below this unit are quartz sandstones of the Purlawaugh Formation, which show sedimentary structures such as cross-bedding, pebble layers and washouts. This sandstone unit is comparable to the nearest units of the Purlawaugh Formation that outcrop about $50 \mathrm{~km}$ away. The Fish Bed is probably the upper unit of the Purlawaugh Formation, but no equivalent outcrop to the Fish Beds is exposed in New South Wales.

SHRIMP (Sensitive High mass Resolution Ion MicroProbe) analysis of zircons was carried out using the SHRIMP RG machine in the ANU Research School of Earth Sciences. The age of the youngest population was $151.55 \pm 4.27 \mathrm{Ma}$, corresponding to the Late Jurassic (Veevers 2000), indicating that the sediment must be this age, or younger if the zircons were all of sedimentary origin. The morphology of the youngest grains does not show any evidence of transportation by water. Examination of the zircons shows that the rock contains a small tuffaceous component. The range of different types of zircons was quite large, and many of them showed clear evidence of a sedimentary history (Dr I Williams, personal communication).

Dulhunty and Eadie (1969) described the "Fish Bed Chert" as a hard, fine limonitic cherty-shale, and Pogson and Cameron (1999) stated "In thin section the unit is a red-brown silty mudstone with compaction bedding features and chips of ?tuffaceous quartz, clayey patches after feldspar and/or lithic fragments, magnetite, ankeritic cement and manganese oxide dendrites." Thin section and chemical analysis shows that the fossil-bearing rocks are largely tuff and sediments derived from the underlying sandstones, some of the tuffs representing one or more very fine-grained ash falls (Prof. R. Arculus, personal communication). EDXA (Energy Dispersive $X$-ray Analysis) has not shown any evidence of carbonate or calcium ions being present, excluding an ankerite $\left[\mathrm{FeCa}\left(\mathrm{CO}_{3}\right)_{2}\right]$ cement (Dr A Christy, personal communication). There is evidence of fine bedding and subsequent compaction. The red-brown colour is post depositional because each block has concentric bands of varying intensity of colour as the iron oxide has penetrated from the joint block boundaries. Manganese dioxide is often found infilling the fossil fish cavities and is generally close to the edge of a block, forming dendrites. Many of the fish and most of the plant fossils are white, having not taken up the red iron oxides. EDXA shows the composition of the infilling of plants and animals is not the same. The plants have been replaced by very fine-grained opalised quartz, whereas kaolin is present with the opalised quartz in the infilling of the fish ( $\mathrm{Dr}$ A Christy, personal communication).

The Talbragar Fossil Fish Bed is probably no more than $60 \mathrm{~cm}$ thick (Percival 1979). The current state of the outcrop is poor as the bed occurs as small blocks of fossil-bearing rock scattered through the soil of a paddock. It is impossible to measure the precise thickness or the boundaries of the bed without excavation. The layers of fossil-bearing rock vary from about $2 \mathrm{~cm}$ to $4 \mathrm{~cm}$ thick, but within these layers the fish are scattered in overlapping layers, rather than all being at the top or all at the bottom of the layer. The exception is some large blocks covered with vast numbers of small fish, some available in part and counterpart. There is no evidence of the original location of these blocks, but it is assumed that this very fossiliferous layer is the upper layer of the deposit, and thus represents one mass-kill event. There is no evidence of desiccation in the sediment, such as mud cracks or aerially exposed surfaces, so this is not a mound spring deposit. It is not an overbank deposit either, as these usually have cyclic layers including sands and coarse-grained layers from flooding, interspersed with soil developments from dry times. The layers that contain an abundance of small fish, which are 
thought to occur at the top of the bed, are very fine grained and represent a period of slow deposition, or a time when the pond was still and suddenly became anoxic. Lower layers have occasional scattered fish that have been deposited along with sediment. Percival (1979) recorded that "it is now thought to represent the erosional remnant of the margin of a freshwater lake bed deposit". Evidence now points to the destruction of the lake by several eruptions of volcanic ash.

The fossils show no preferred orientation, although most are laterally flattened. Only one of several hundred specimens is dorso-ventrally flattened. Some of the smaller individuals show dorsal flexion. This flexion of the spine could represent greater flexibility of the juvenile individuals, or could possibly be a result of them dying in suddenly anoxic water as the result of an ash fall. The dorsal flexion of the small specimens was also commented upon by Waldman (1971) in his description of the fish in the Cretaceous Koonwarra beds in Victoria. He considered that particular assemblage, which includes a large number of the closely related species, Leptolepis koonwarri Waldman, 1971, was due to winterkill and claimed the flexion is due to asphyxia of the individuals when the pond was covered by ice. As is noted later in this paper, many of the fish are preserved with their mouths open, which could support the idea of anoxia.

Plant fossils are commonly associated with the fish. None of these represent plants growing in situ, and there is no evidence for any water dwelling plants. The plant material consists of twigs, individual leaves, occasional cones, and very small fragments. Some beds have masses of very finely shredded plant material.

The area surrounding the lake was heavily forested with an araucarian pine, Agathis jurassica (White 1981). The fine detail of plants and fishes preserved implies an anaerobic burial environment. Most of the fish are intact with very few examples of disarticulated bones, indicating a lack of postmortem turbulence, predation and decay. The plant fragments show venation and cell structure, thus showing no signs of decay or transportation.

Etheridge and Olliff (1890) described one example of a cicada named Cicada? lowei found in the fish beds, and further examples of insects have since been found. The Australian Museum houses a collection of Talbragar insects that has not been studied in detail. These insects are the only preserved evidence of a food source for the fish. The insects are apparently found in the upper layer where the fish fossils are most concentrated (R. Beattie, personal communication). Since none have been found in the lower layers where the fish are more scattered it may indicate that the insects were trapped by the ash fall that finally filled in the pond.

\section{Materials}

The specimens described in this study come from three sources: Australian Museum, Sydney, prefix AMF (30 specimens); NSW Geological Survey, Sydney, prefix MMF (107 specimens); Australian National University, Canberra, prefix ANU (106 specimens).

Where more than one fossil appears on a numbered specimen, the individual fossils have been allocated a letter suffix to distinguish them, eg MMF36743b.

Some material mentioned in text and figures relates to specimens in the Natural History Museum, London, prefix BMNH.

\section{SYSTEMATICS}

Subclass Teleostei Muller, 1844

Family Leptolepididae (Agassiz, 1833-44)

Genus Cavenderichthys Arratia, 1997

\section{Synonymy}

See Arratia (1997:19).

\section{Diagnosis}

Small teleosts ranging from about $4 \mathrm{~cm}$ to $12 \mathrm{~cm}$; head with short snout; lower jaw projecting anteriorly; fusiform body. Frontal bone short anteriorly. Suborbital bone absent. Quadratemandibular articulation below anterior half of orbit. Elongated symplectic and hyomandibular, as well as ventral limb of preoperculum. Lower jaw with deep coronoid process and wide leptolepid notch. Hyomandibular with a preopercular process. No suprapreopercular bone. Infraorbital sensory canal with very few tubules; generally four broad tubules on lower limb of preoperculum, one at the angle, and one on vertical limb. Anterior ceratohyal short and usually not fenestrate; with six thin arcinaciform branchiostegal rays, and three or four spathiform branchiostegal rays associated with the posterior ceratohyal. 35-45 vertebrae with autogenous neural arches in abdominal region and fused neural and haemal arches in caudal region, with 20-26 pairs of ribs. Midcaudal autocentra thin, ring-like, with or without a longitudinal crest on lateral surface. 12 pectoral rays, 12 pelvic rays, 12 dorsal rays +3 procurrent dorsal rays, and 10 anal rays. Pelvic, dorsal and anal rays branching distally into 4 lepidotrichs. Preural centrum 1 with short neural spine. Three or rarely four epurals; seven hypurals and five uroneurals; $10+9$ principal caudal rays. Well-developed dorsal processes on bases of innermost principal caudal rays of dorsal lobe of caudal fin absent. Two "urodermals". Six basal fulcra on upper lobe of caudal fin. 
Remarks

This diagnosis is based on Arratia (1997:19). However changes have been made where examination of new material has added information that contradicts the original diagnosis. For example, Arratia cited a deep body, the hyomandibular lacking a preopercular process, the lower jaw lacking a leptolepid notch, 12 or 13 branchiostegal rays, 43-45 vertebrae, $25-27$ ribs, nine hypurals, seven uroneurals, and a lack of epipleural bones. These features are discussed later.

\section{Cavenderichthys talbragarensis (Woodward, 1895)} Figures 1-22

Leptolepis talbragarensis Woodward, 1895: pp. 21, 22, pl. 6, figs 1-8.

Leptolepis lowei Woodward, 1895: pp. 22, 23, pl. 6, figs $9,10$.

Leptolepis gregarius Woodward, 1895: pp 23-24, pl. 4, figs $8-10$, pl. 5, fig. 5, pl. 6, figs 11, 12.

\section{Material Examined}

Holotype

MMF81. This specimen has been examined, but not used in the current description. It was named as the type specimen by Woodward (1895) and appeared as Plate 6 , figure 4.

\section{Paratypes}

The following specimens, housed in the
Australian Museum, Sydney, are paratypes, described by Woodward (1895). The old numbers have prefix $\mathrm{MF}$, and have been replaced by new numbers with prefix AMF. AMF120525 (MF276), AMF120509 (MF276), AMF120505 (MF276), AMF120498 (MF276), AMF120512 (MF276), AMF120497 (MF276).

\section{Other material}

The following specimens have been examined, provided latex casts in most cases, and are quoted as examples in the text.

AMF27069, AMF4133, AMF51899, ANU54916, ANU54940, ANU54946, ANU54956, ANU54962, ANU54968, ANU54970, ANU54975, ANU54976, ANU54977, ANU54980, ANU54982, ANU54983, MMF13555, MMF13561a, MMF13564, MMF13569, MMF13599b, MMF13603k, MMF13606a, MMF13734a, MMF36716, MMF36718, MMF36721, MMF36728, MMF36729, MMF36730, MMF36732, MMF36732a, MMF36733, MMF36735, MMF36737, MMF36743, MMF36743a, MMF36743b, MMF36746, MMF36753a, MMF36758a, MMF36759, MMF36761b, MMF36773, MMF36778.

\section{Description}

\section{Olfactory region}

The rostral is evident on several specimens, including ANU54956 (Figure 2A) and MMF13555 (Figure 2B), and is small and almost shaped like an isosceles triangle, with the apex anterior. The two lateral margins are slightly concave, and the posterior

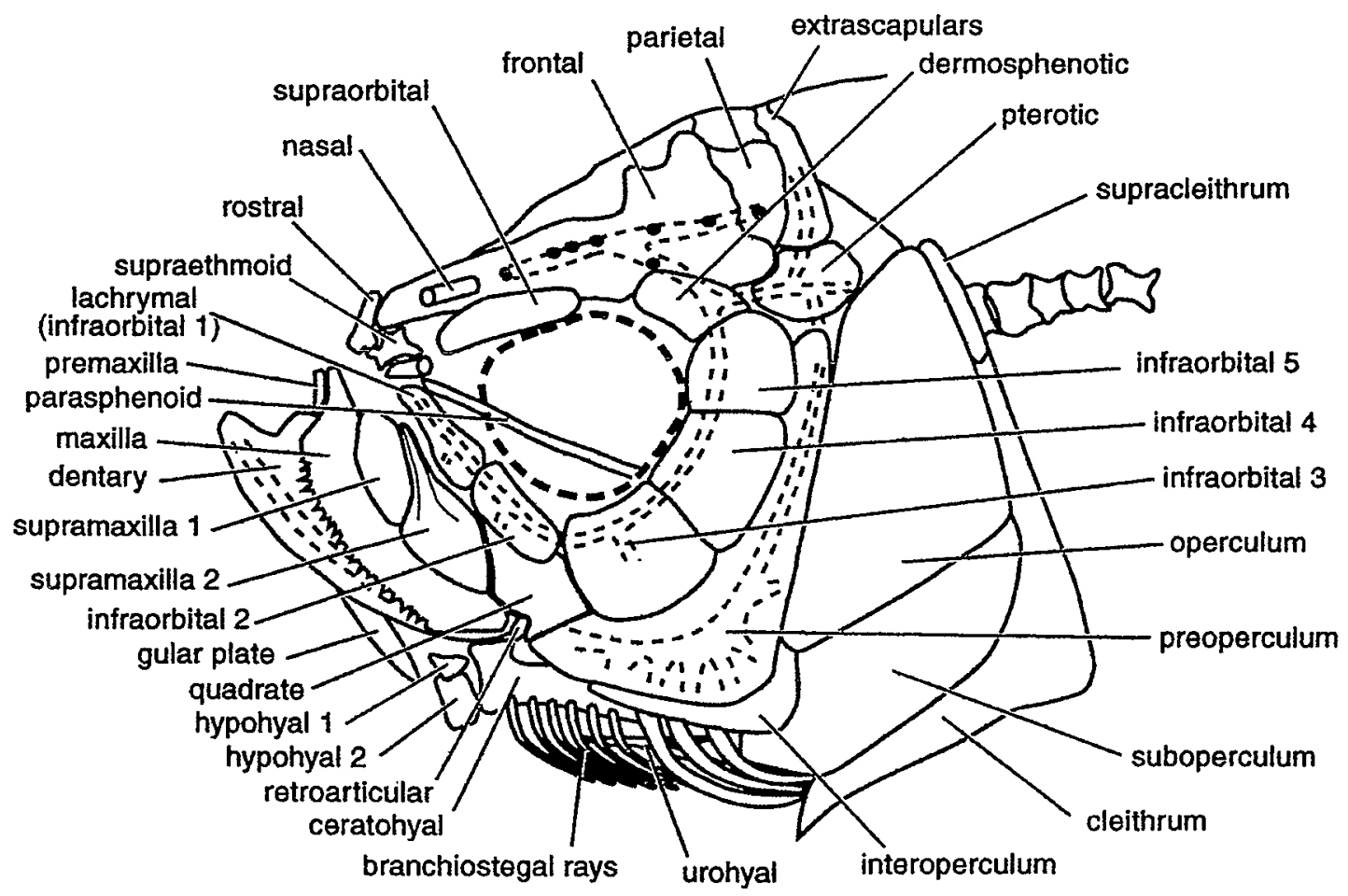

Figure 1 Cavenderichthys talbragarensis. Reconstruction of head, lateral view, based on MMF36716. 

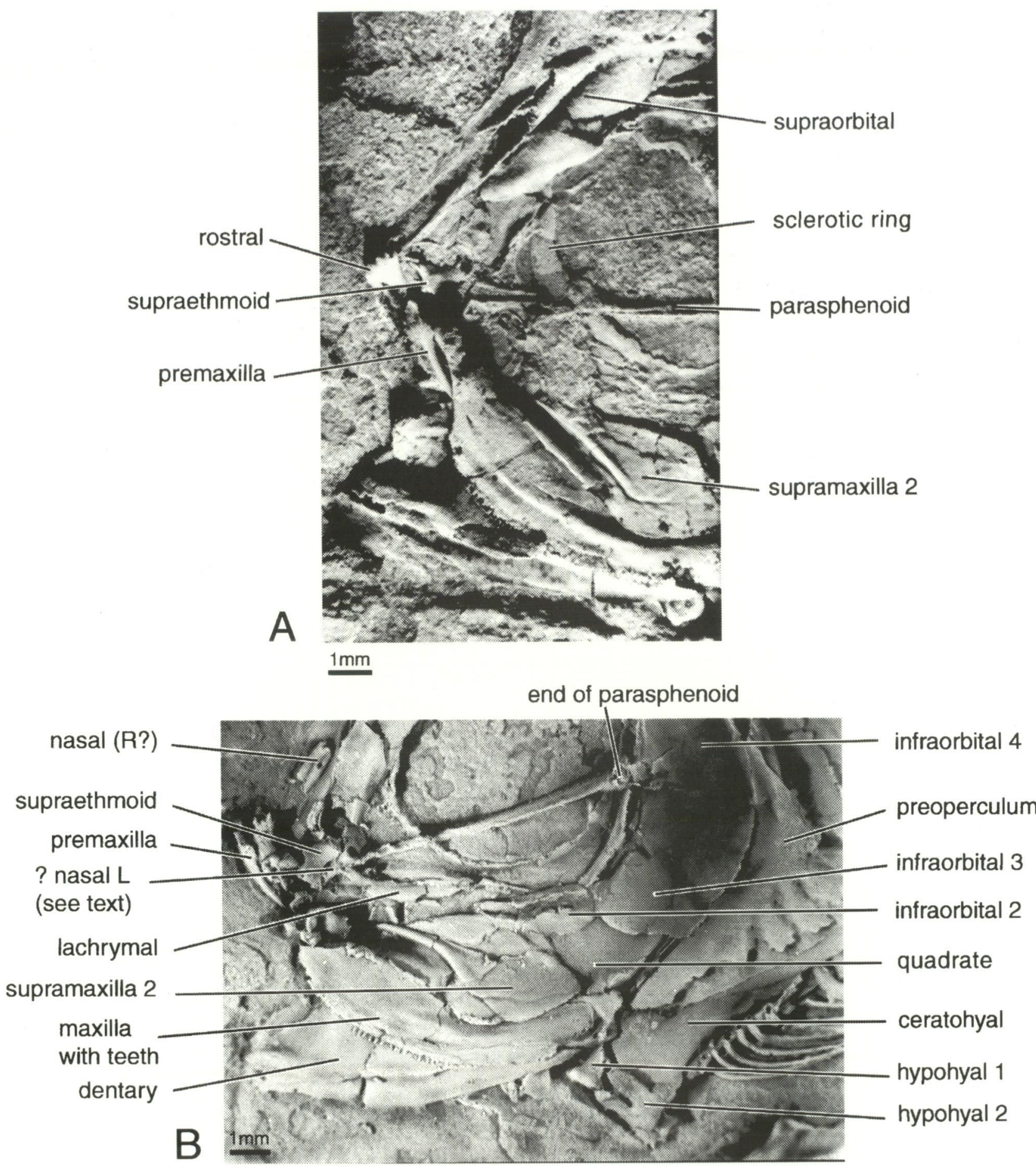

Figure 2 Cavenderichthys talbragarensis. Details of anterior head. A, this view of the front of the head of ANU54956 shows unusual detail of the anterior bones. B, the anterior of MMF13555 shows the premaxilla and nasal bones. On the supermaxilla 2 it is possible to see traces of the path of nerves. The preservation of teeth on the maxilla is unusually clear. The posterior of the parasphenoid can be see to be enlarged.

margin is crenulated where it articulates with the frontal. In ANU54956 it is disarticulated from the frontal, but the posterior margin is clear (Figure 2A). This bone articulates with the maxilla and premaxilla and presumably with the supraethmoid, although this articulation has not been observed. The ethmoid has not been observed in this material.

The supraethmoid is a small median bone that is under the anterior part of the frontal-rostral and probably is the ossified covering of the ethmoid cartilage. Two specimens, ANU54956 (Figure 2A) and MMF1355 (Figure 2B), show the supraethmoid to be roughly Y-shaped, with the two branches being posterior. The articulation of these branches with other bones cannot be determined in these specimens. 


\section{Otic region}

The generally poor preservation of the otic region results from it overlying the back of the braincase causing it to be usually crushed, and is only known from one specimen (Figure 7A). The pterotic is roughly rectangular, and located dorsal to the preoperculum and posterior to the dermosphenotic. It carries the sensory canal where it branches off to the preoperculum. The parietals are medial to the pterotic. Only one specimen has an identifiable pterotic (Figure 7A).

\section{Dorsal roofing bones}

A small cylindrical bone on MMF13555 (Figure 2B), just ventral to the supraethmoid, has unclear relationships with other bones. It appears to carry a sensory canal, and in the flattened fossil it appears to be adjacent to the anterior end of the parasphenoid. This bone may be the left nasal. The right nasal is well exposed on MMF13555 (Figure 2B), having been detached during fossilization. It is identified on its tubular form and containing the supraorbital sensory canal. It sits adjacent to the anterior part of the frontal, where the sensory canal emerges from under the ridge of covering that protects it in the region above the supraorbital.

Frontals are the largest skull roof bones, almost the same size as the dentary bones. They are narrow at the front and become wider behind the eye. The suture between them is straight in the narrow region, and then bends back and forth in the wider region. The frontals carry the sensory canal, with pores occurring at the front, above the centre of the supraorbital bone, and at the end of a branch where the canal curves down around the eye. The canal is close to the surface of the bone and is covered by a ridge in some specimens in the anterior narrow part of the frontal, e.g., MMF13564 (Figure 3B). In other cases the delicate ridge has been removed and a canal is visible, e.g., ANU54916, MMF36781, MMF36735, MMF36753a (not figured). About two thirds of the distance from the anterior of the frontals is a prominent pore, behind which the sensory canal branches, with one branch leading into the parietals where it terminates at a pore (MMF36753a, Figure 6A). The other branch turns ventrally and passes into the dermosphenotic. Where the frontal broadens out, it forms the margin of the orbit between the supraorbital and the dermosphenotic.

The parietals are generally rectangular in form and meet medially by an irregular suture. The sensory canal crosses them from the frontals, but does not emerge posteriorly. The parietals occur directly behind the frontals and anterior to the extrascapulars.

The extrascapulars (Figure 6A) are smaller than the parietals and are posterior to them. They carry a

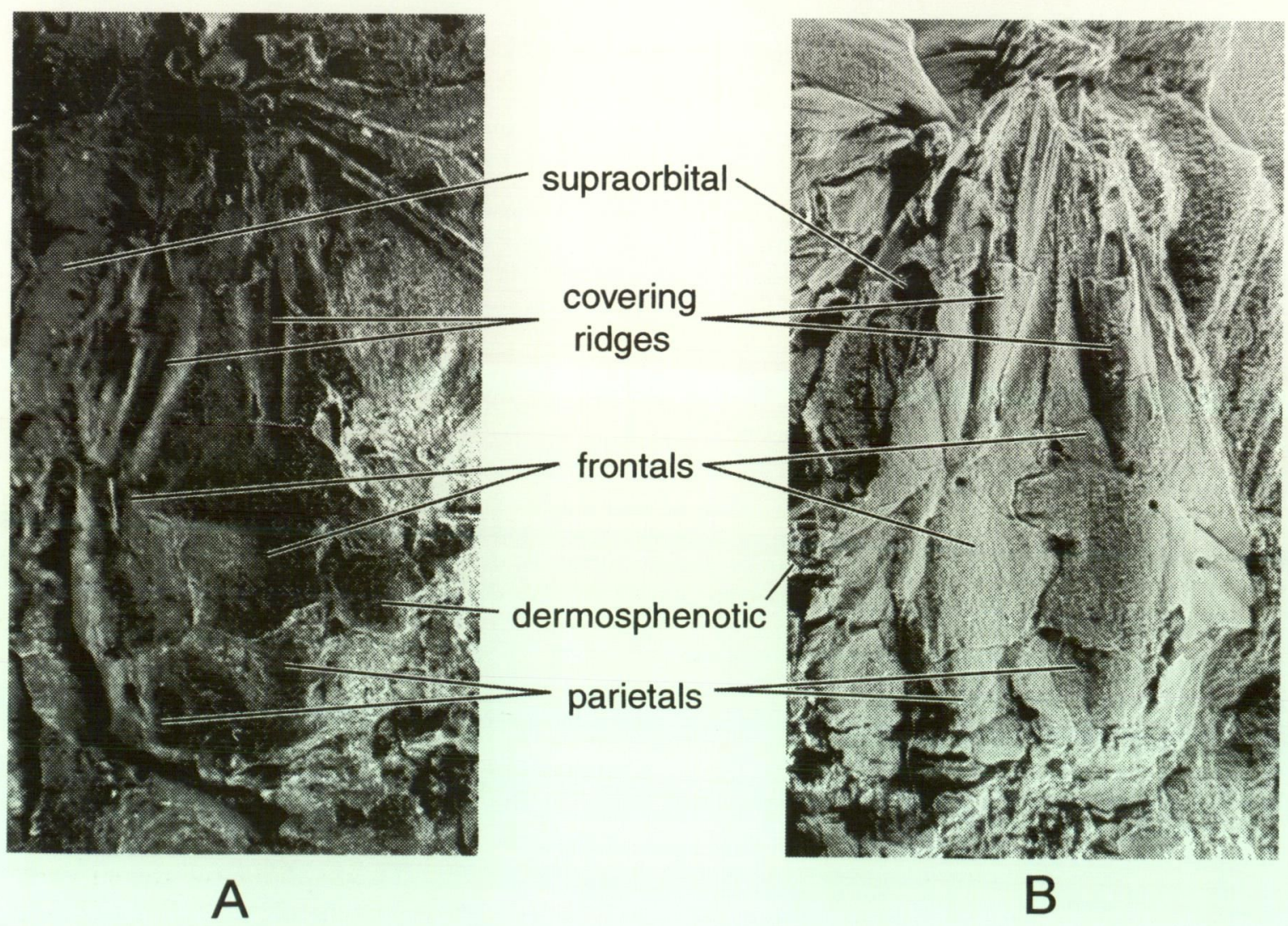

Figure 3 Cavenderichthys talbragarensis. Skull roofs. A, this photograph of a latex peel of the skull roof of MMF36728 is a rare example of this view. B, on this peel of MMF13564 it is possible to see even more detail including the mid-line suture and several pores for the emergence of nerves. 


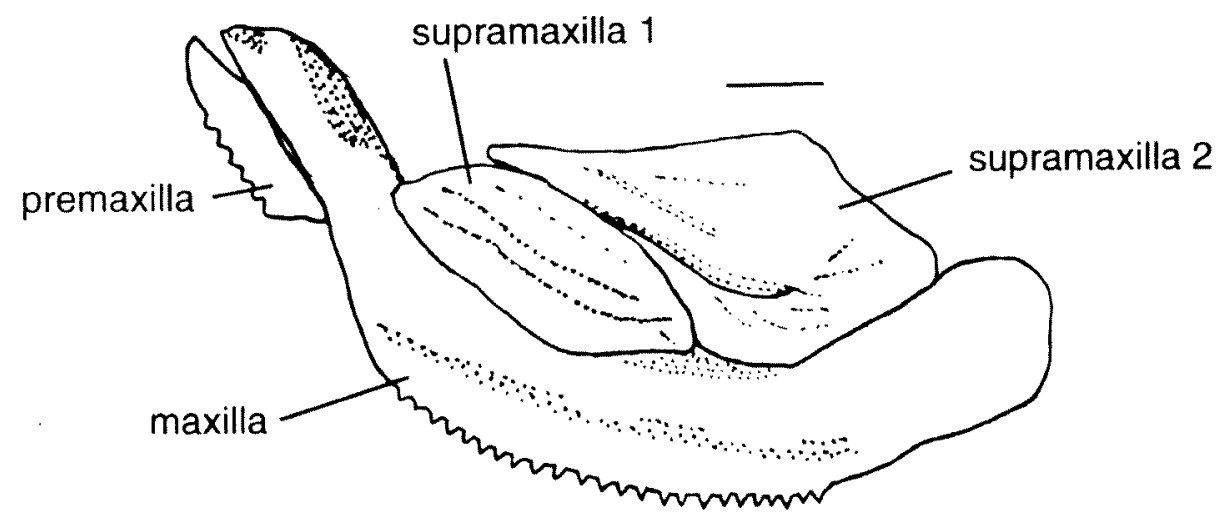

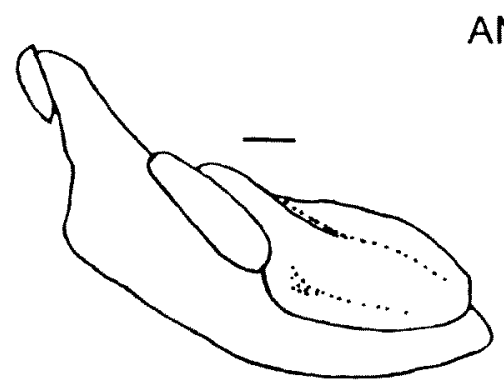

MMF13603a

ANU54956

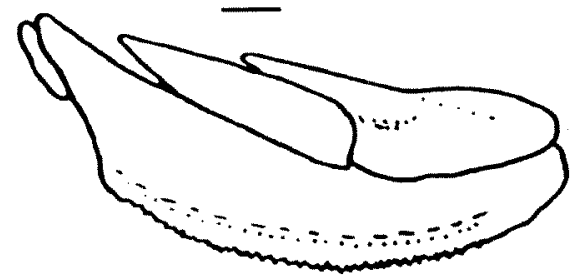

MMF13603k

A

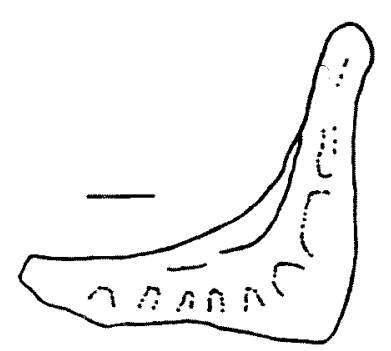

ANU54916

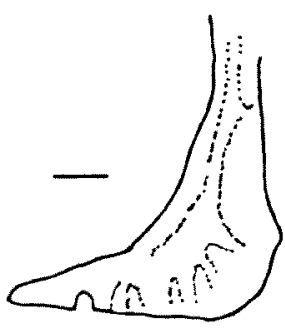

ANU54962

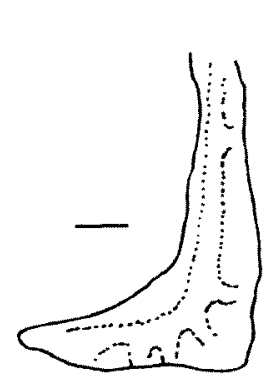

ANU54946

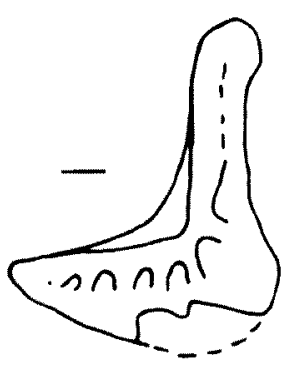

MMF36730

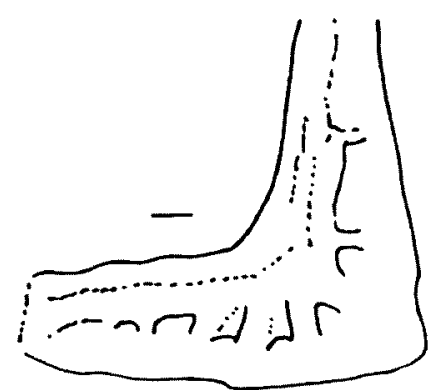

ANU54956

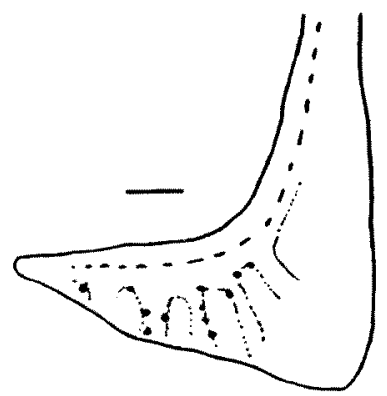

MMF36728

B

Figure 4 Cavenderichthys talbragarensis. A, sketches of the differences in arrangements of bones in the upper jaw. This is natural intra-species variation, and is as much a function of differences in preservation as differences between individuals. $B$, sketches of the variations in arrangement of the preopercular canal on the preoperculum. Scale bars $=1 \mathrm{~mm}$. 
sensory canal with several pores. They are the posterior bones of the roof of the skull, but in many specimens they are crushed and difficult to interpret. Figures $3 \mathrm{~A}$ and $3 \mathrm{~B}$ are photos of the skull roofs of MMF36728 and MMF13564 respectively.

\section{Lateral skull bones}

The premaxilla (Figures 2A, 2B, $4 \mathrm{~A}$ and $5 \mathrm{~A}$ ) is small and mobile, and because of this it is often lost due to poor preservation. It fits into a concavity on the front of the maxilla (see below). There are about 6 small teeth on the premaxilla, which lies adjacent to the rostral bone and the supraethmoid, (ANU54956, Figure 2A) but this region is not usually seen clearly. Other non-figured specimens showing the premaxilla include MMF36732a, MMF36778, MMF13555, ANU54916, and ANU54968.

The maxilla has along its ventral margin a row of small, even teeth, which can be seen on specimens ANU54956 (Figure 4A), ANU54976 (Figure 5A), and MMF36729 (not figured). This margin is a smooth gentle convex curve ventrally, with a small arcuate toothless concavity at the front to accommodate the premaxilla. The maxilla and the premaxilla are certainly not fused in any way, as the premaxilla is often detached from the maxilla, but their articulation is not obvious. The posterior end of the maxilla is a smooth semicircular curve and is connected to the coronoid process of the mandible by a flat maxillomandibular ligament (Lauder 1980). The anterior end of the bone has a peg-like process, which enables it to articulate probably with the vomer, ethmoid and palatine in a similar manner to Amia (Lauder 1980). This means the maxilla is fixed at the anterior end and free to swing forward and backward from the posterior. When the mouth is agape, the maxilla swings forward, and is often found preserved in this position. Teeth form the margin of the gape when the maxilla is fully protracted. When the mouth is closed the maxilla is pulled backward, and passes outside the dentary, coming to rest on the ridge on the dentary formed by the heavy ossification around the Meckelian cartilage. The outside surface of the maxilla has a ridge running along the middle from the anterior end. Of 142 specimens in which it is possible to distinguish the state of the maxilla, 83 have the maxilla wide open.

There are two supramaxillae, the anterior being a small smooth oval bone that on-laps the anterior part of the dorsal margin of the maxilla (MMF36732a, Figure 6B). The posterior supramaxilla has a generally oval shaped base onlapping the maxilla, but it also has a long thin slightly curved process extending anteriorly under and above the anterior supramaxilla. This process has a thin ridge and groove that extend from the tip down into the body of the bone. The surface of the body of the posterior supramaxilla has a radiating pattern of grooves and small ridges, which appear to represent a point of ligament attachment. The maxilla and the two supramaxillae move as a unit and are generally found joined together. Figures 5, 6 and 7 illustrate the various structures of the upper and lower jaws.

\section{Circumorbital series}

The system of naming all lower circumorbitals as infraorbitals, as used by Cavender (1970), Nybelin (1974), Patterson (1977) and Arratia (1997) has been used here. Confusion can arise when some bones are not preserved, e.g., infraorbital 1 or lachrymal, and the terminology used by Norden (1961), based on living fish, which clearly identifies specific bones, was used initially by the author to establish relationships. However, the modern terminology has been used to be consistent with contemporary publications.

A single supraorbital bone is the anterodorsal bone of the circumorbital series. It is a long thin oval with a slight upwards curve to follow the dorsal margin of the eye. The ends of the bone are rounded and there is no sensory canal. It forms the anterodorsal margin of the orbit (ANU54956, Figure 2A and MMF36728, Figure 3A).

The infraorbital 1 , also called the lachrymal, (MMF13555 Figure 2B) is small, forming the lower anterior rim of the orbit, and contains the terminus of the infraorbital canals (Norden 1961). It is a dermal bone external to the ectopterygoid, fitting into the series around the eye. It is narrow anteriorly and broadens posteriorly and is almost triangular in nature with the apex towards the front. It carries the sensory canal, but due to the state of preservation it is impossible to determine if it is the site of the terminus of the infraorbital canal.

Specimens MMF36728 (Figure 5C), AMF51899 (Figure 7A) and MMF36735 (not figured) show the continuation of the infraorbital series. There are four bones all about the same size and depth around the ventral and posterior part of the eye. They all carry the sensory canal. The first one is the infraorbital 2. In Cavenderichthys talbragarensis it has a roughly trapezoid shape. A branch off the canal is directed ventrally. The infraorbital 2 is not as deep as the subsequent ifraorbitals. Its ventral margin is level with the ventral margin of the infraorbital 1 in front, but at the back it is about half as deep as the infraorbital 3.

Infraorbitals 3-5, which are all about the same depth, form the posterior rim of the eye. A suture between infraorbitals 3 and 4 always appears in compressed forms to be adjacent to the posterior end of the parasphenoid. In all the specimens illustrated in this article there is an easily identified bone, infraorbital 3, which occurs anterior to the bend of the preoperculum. Dorsal to this bone is 

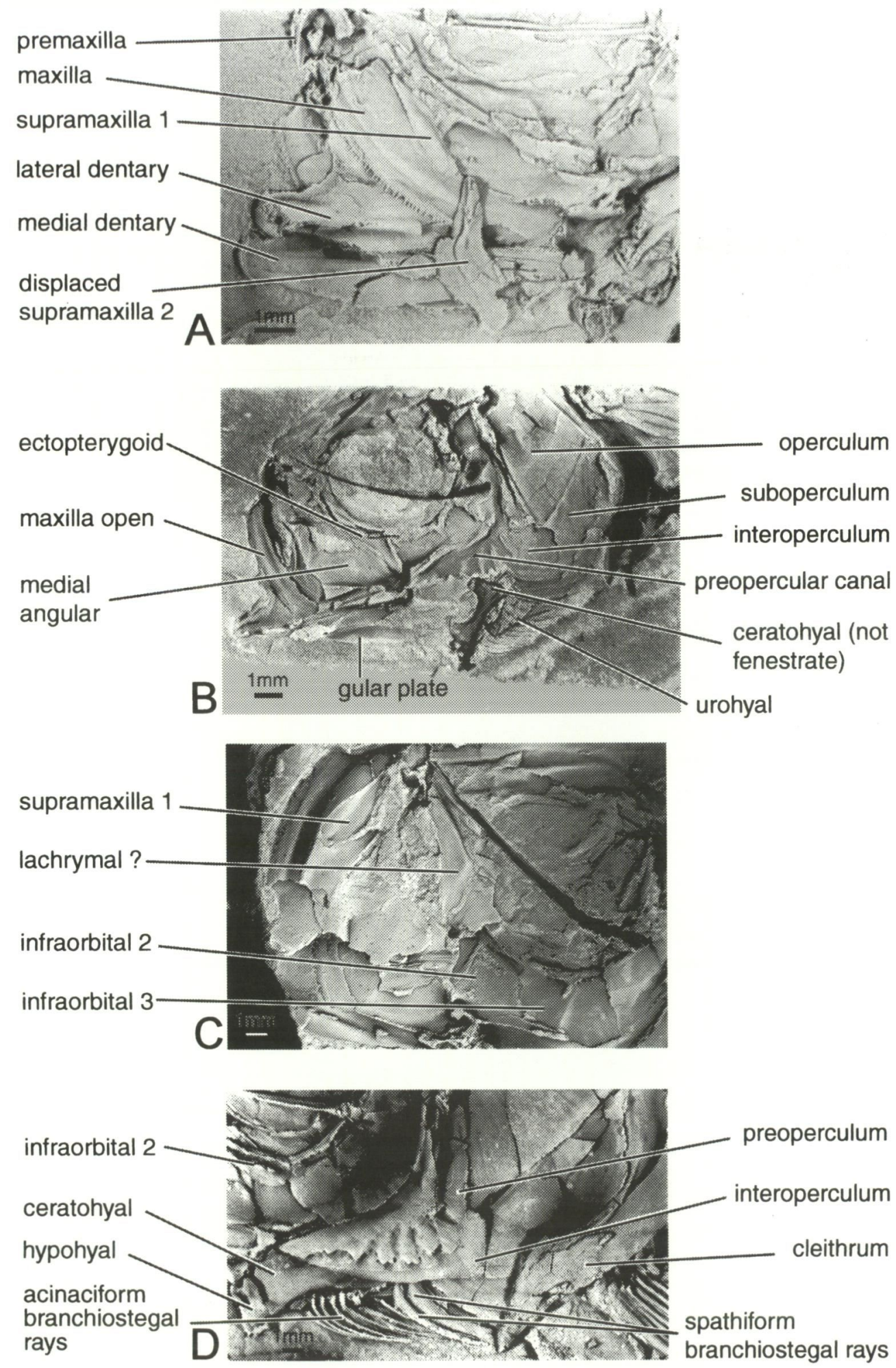

Figure 5 Cavenderichthys talbragarensis. A, detail of the jaws of ANU54976. Left and right dentaries are both visible, and well preserved teeth on the maxilla. Supramaxilla 2 has been displaced but its medial ridge is clear. B, medial view of MMF36732a, showing the ectopterygoid and bones of the circumorbital series. In this specimen the ceratohyal is clearly not fenestrate, and the delicate nature of the urohyal is obvious. C, MMF36728 has well preserved bones of the circumorbital series, including the lachrymal. D, in this detail of the posterior ventral region of the head of MMF13555, the ceratohyal is partly covered by the preoperculum, but the relationship of the two forms of branchiostegal rays to the ceratohyal is clear. Two hypohyals are visible at the anterior of the ceratohyal. 

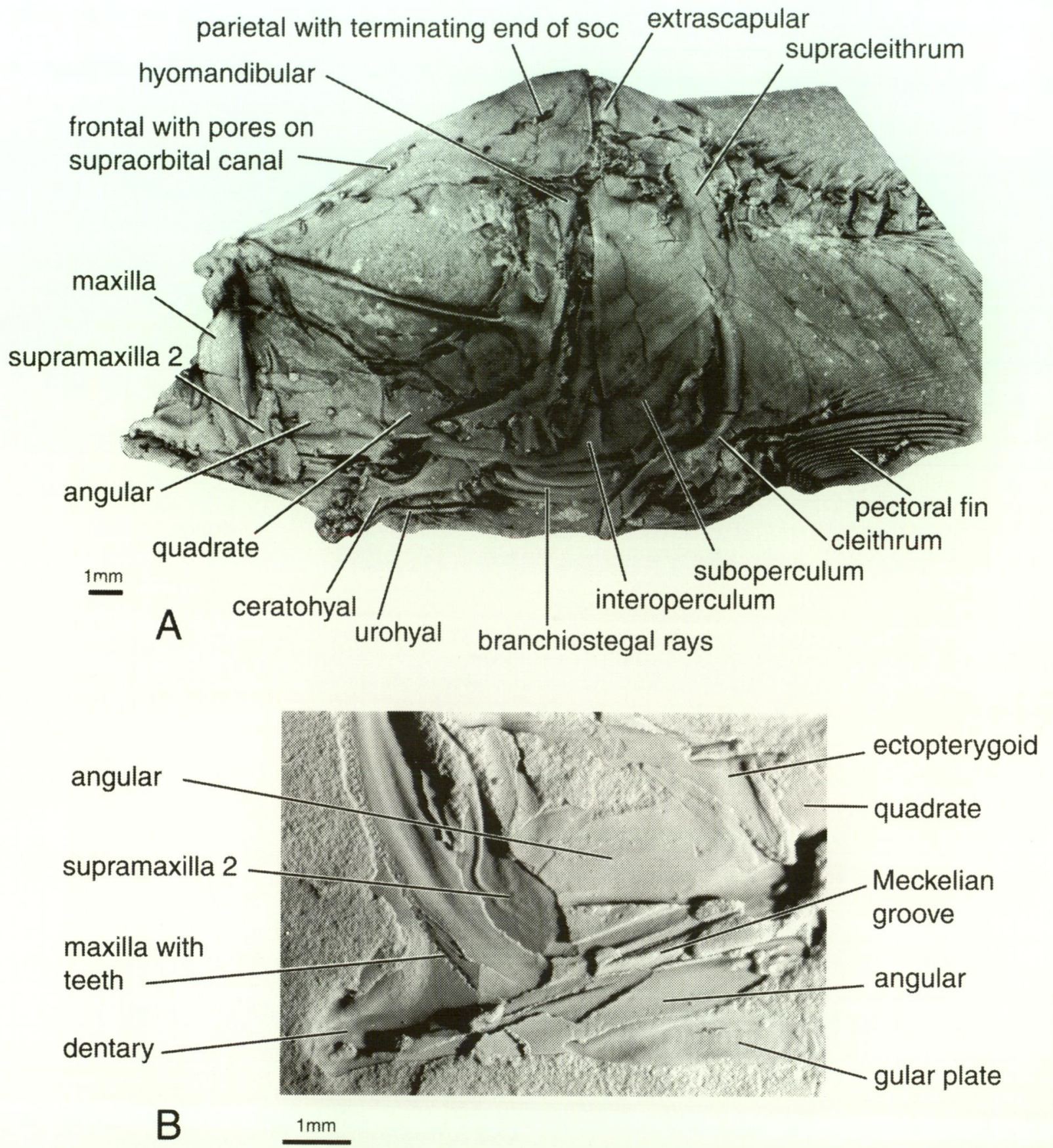

Figure 6 Cavenderichthys talbragarensis. Heads showing the maxilla in the forward open position. A, this photograph of a peel of MMF36753a includes a ceratohyal that is not fenestrate, and very clear pores on the supraorbital canal. The characteristic position of the parasphenoid appearing to bisect the orbit is well demonstrated. B, the detail of the jaws of MMF36732a is taken directly from the specimen. The location of the Meckelian cartilage present along the interior surface of the dentary is obvious.

infraorbital 4, a squarish bone that in Cavenderichthys is as deep as infraorbital 3. The most dorsal infraorbital 5 (Figures 7A, 7B, 8A) is not squarish but roughly triangular with rounded corners, the apex pointing dorsally. These bones lie anterior to the preoperculum and overlap it slightly. Infraorbitals 3 and 4 have approximately rectangular shapes with curved margins. There are no branches of the sensory canal in infraorbitals 4 and 5 (see MMF36761b, Figure 7B, and MMF13599b, Figure 8A).
Dorsal to infraorbital 5 is the dermosphenotic, or infraorbital 6 (AMF51899, Figure 7A). Norden classifies the dermosphenotic as a "small, dermal postorbital bone, which bears a triradiate sensory canal." In many specimens this bone is crushed and difficult to identify, but it is possible to see in several specimens that it carries a junction of the sensory canal where it descends from the frontal, continues into the highest infraorbital, and branches posteriorly towards the pterotic. It makes part of the posterior rim of the orbit. 

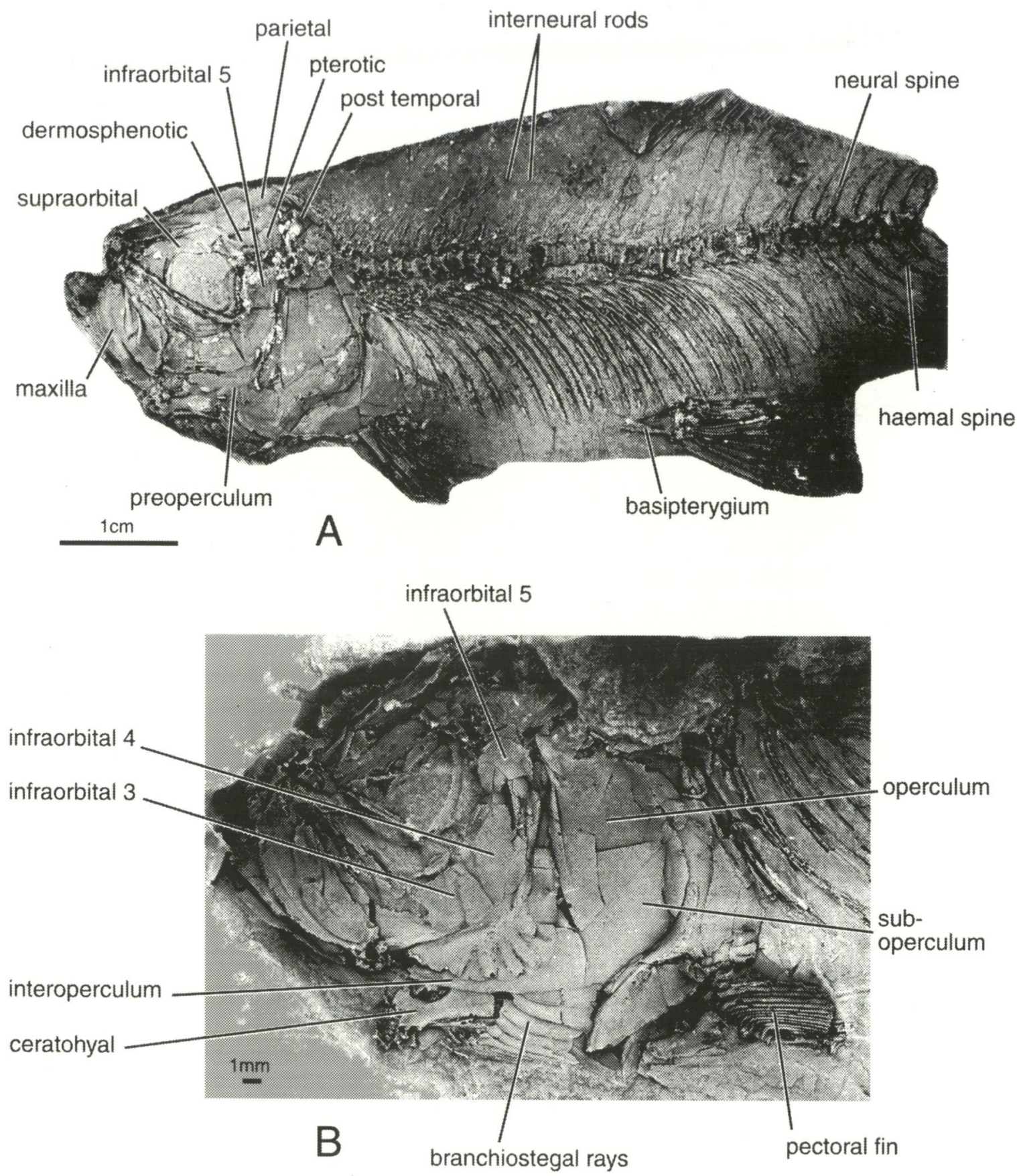

Figure 7 Cavenderichthys talbragarensis. Heads showing the jaws closed. A, F51799, infraorbitals 3-5 can be identified as well as the pterotic and dermosphenotic. In the pleural region the vertebral column is well preserved and interneural bones are visible. The basipterygium can be seen supporting the pelvic fin. $\mathrm{B}$, on the specimen MMF36761b the bones of the opercular series and the infraorbital bones can be easily identified. The spathiform branchiostegal rays are seen posterior to the ceratohyal. The path of the preopercular canal clearly shows five branches.

\section{Preoperculum}

A commonly preserved bone is the preoperculum, well seen on MMF36730, MMF36759, ANU54916, ANU54968 and ANU54940 (see Figure 4B). It lies behind the infraorbital series, and is not part of the opercular series. The bone is arcuate, with an angle of approximately $110^{\circ}$ between the dorsal and ventral limbs, and it carries a prominent branch of the sensory canal. The dorsal margin of the upper limb is often crushed. The postero-ventral margin is smoothly curved, making a more acute angle than the anterior margin. The anterior margin of the ventral limb extends to a point lateral and just posterior to the articulation of the lower jaw. The sensory canal is carried close to the outer surface of the bone, and continues onto the mandible. When the external surface is preserved it is apparent that the canal makes a ridge on the surface, with small pits at the ends of side branches opening to the surface. Often the canal is preserved by infilling with fine-grained white material, indicating that it was closed at the time of 
death and has subsequently been filled with material that is different from the typical matrix. The canal is located closer to the anterior margin than the posterior, with a series of branches running down towards the posterior margin, on average six branches, sometimes seven and occasionally five. There is usually only one branch on the dorsal limb, about halfway up, with the others evenly spaced, three along the ventral limb and two adjacent to the bend. The branches are broad and tend to widen away from the main canal. Illustrated examples of the preoperculum are Figure $4 B, M M F 13555$ (Figure 5D), MMF36732 (Figure 5B), and MMF13599b (Figure 8A).

Suprapreoperculum and suborbital bones are lacking.

\section{Opercular series}

The shape of the operculum is roughly triangular with the most acute angle dorsal. The top is sometimes involved in the crushing at the back of the braincase, but when well preserved it can be seen to be smoothly rounded. The anterior margin is approximately perpendicular to the line of the vertebral column. The posterior margin is convex posteriorly. The ventral margin is straight and inclined down towards the front, and overlaps the suboperculum.

The suboperculum has the appearance of being an isolated continuation of the operculum (Figures $6 \mathrm{~A}$ and $7 \mathrm{~B}$ ). The anterior and posterior margins follow the same lines. The ventral margin of the suboperculum follows the line of the ventral surface of the fish and overlaps the branchiostegal rays. It is adjacent to the cleithrum.

The interoperculum is a triangular bone, ventral to and partly hidden by the preoperculum. It often overlaps the branchiostegal rays, and is adjacent to the suboperculum. It can be seen in specimens MMF13555 (Figure 5D), MMF36732a, MMF36728, ANU54976, ANU54983, MMF36761b (Figure 7B), MMF36753a (Figure 6A), and MMF36735.

Six thin acinaciform branchiostegal rays are regularly associated with the ceratohyal, presumably with a ligamentous connection between them. They leave the ceratohyal ventrally then curve around to point posteriorly (Figure 5D). They extend toward the cleithrum and end as thin points, floating freely. The left and right rays are separated by the $Y$-shaped urohyal.

There are three or four spathiform branchiostegal rays that also seem to be connected to the epihyal (MMF13555, Figure 5D and MMF36761b, Figure 7B). They are dorsal to the thin rays but curve around in a similar fashion and parallel the base of the suboperculum. This maximum number of 10 branchiostegal rays is less than the 12 or 13 counted by Arratia (1997) in her diagnosis of Cavenderichthys. This may be because sometimes the rays from both the left and right sides are visible.

\section{Palatal bones}

The generally poor preservation of the front of the head means that it has not been possible to identify the vomer, which should be a median toothed bone between the two premaxillae. In comparison, the appearance of the parasphenoid bisecting the orbit is one of the typical features of Cavenderichthys talbragarensis, e.g., Figures 2A, $2 \mathrm{~B}, 5 \mathrm{~B}, 5 \mathrm{C}, 6 \mathrm{~A}, 7 \mathrm{~A}, 8 \mathrm{~A}, 8 \mathrm{~B}$. The parasphenoid is a median dermal bone that forms the roof of the mouth, so when the fish is laterally compressed it appears across the large eye socket. This bone is thin dorso-ventrally, and it is slightly concave dorsally. The rear of the parasphenoid is generally hidden behind the postorbitals, so details of its relationship with the brain case cannot be determined. One figure of MMF13555 (Figure 2B) shows an expanded posterior end. The anterior end extends to the front of the head and probably articulates with the vomer. The line of the parasphenoid is inclined upwards towards the front, making an angle of about $120^{\circ}$ with the line of the spine.

\section{Mandible}

The dentary is the major bone of the lower jaw; see Figures 2B, 5A, 9A, 9B and MMF36730, MMF36733, MMF13734a (unfigured). The Meckelian canal which carries the Meckelian cartilage lies close to the internal surface, and adjacent to this on the external surface there is a prominent ossification of the dentary covering the sensory canal, making a ridge along the external surface. This ridge is sometimes removed or damaged, leaving a deep canal. If the surface is preserved there are seen to be two or three pores along the path of the canal, as shown by Arratia (1997: 21). The front of the dentary always protrudes beyond the line of the maxilla, whether the gape is open or closed. The ventral margin of the dentary forms a smooth gentle curve, passing posteriorly into the angular. The anterior margin of the dentary is tightly rounded. The anterior-dorsal margin is slightly inclined and sometimes carries about 6-10 small teeth. These are not commonly seen, even when the maxilla teeth are clearly preserved. They may be just very small, or possibly they are not always present. Posterior to the toothed surface the margin of the dentary forms a downward notch before rising steeply to the coronoid process (Figures 9A, 9B). This notch is equivalent to the "leptolepid notch" referred to by Nybelin (1974), Patterson (1977), and Arratia (1997) (see later comparison with other species). The notch is smoothly curved, is higher on the internal surface and makes a channel down towards the outer 

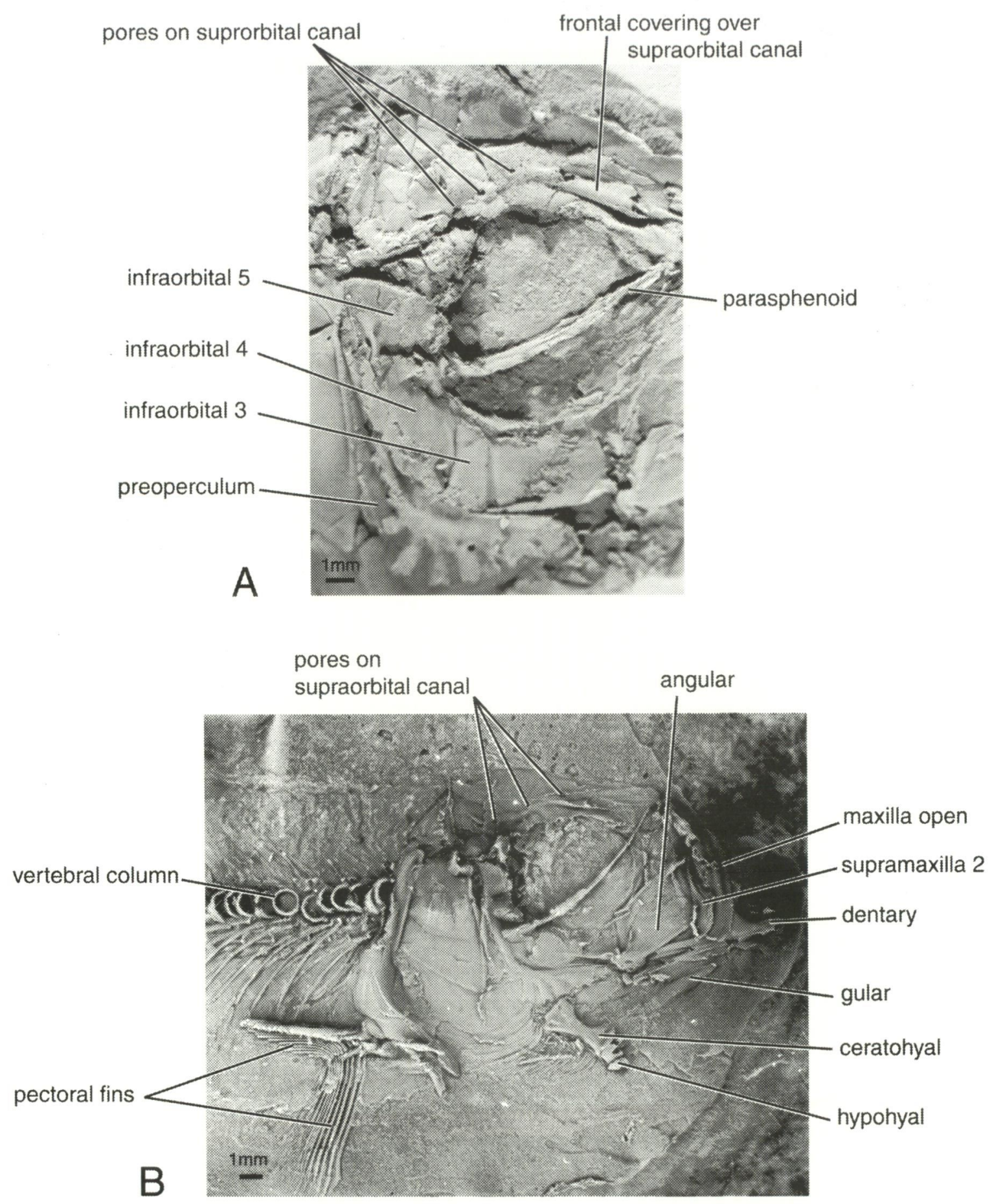

Figure 8 Cavenderichthys talbragarensis. A, MMF13599b, some detail of the roof of the skull is seen, including pores on the supraorbital canal. Infraorbitals 3-5 are clear. B, this photograph of a peel of MMF36732a shows uncommon detail of the pectoral fins, the structure and degree of ossification of the anterior vertebrae, and the pores on the supraorbital canal. The gular plate is preserved below the dentary, and the ceratohyal not fenestrate.

surface. It is much wider that the notch illustrated by Nybelin in Leptolepis coryphaenoides, but it occurs in the same location. The dorsal margin of the coronoid process is formed anteriorly by the dentary and posteriorly by the angular. The angular and dentary are always found closely associated, together with the retroarticular.

The angular fits into a V-shaped notch on the back of the dentary and can be seen on MMF13734a
(Figures 9A, 9B). It is thin dorsally and thickens ventrally adjacent to the Meckelian canal. The postero-ventral corner, which incorporates the fused articular process, articulates with the quadrate. The angular makes up about the posterior third of the ventral margin of the mandible. There is not sufficient information to determine a true relationship between the angular and articular due to the lack of exposure of this area. 

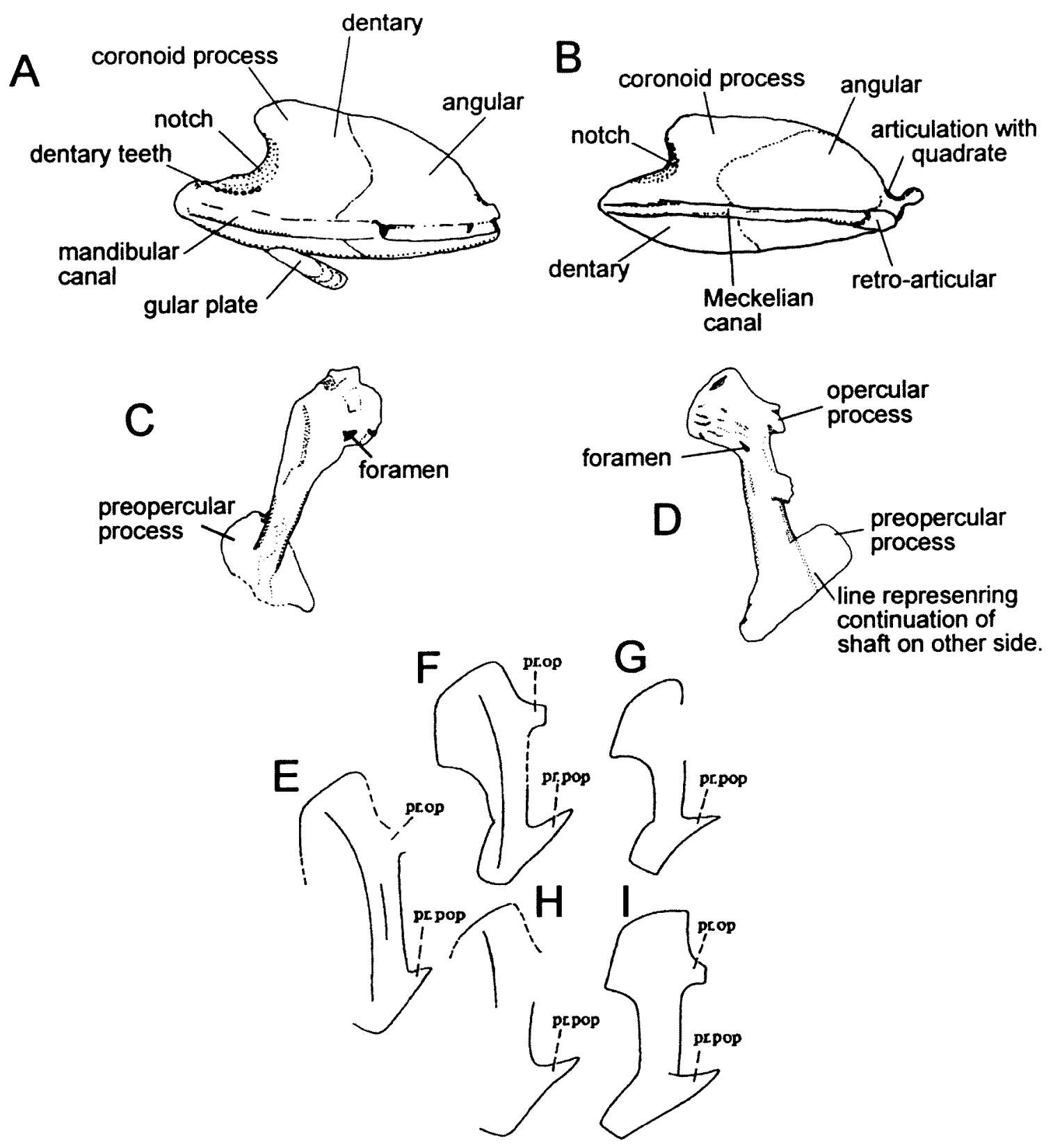
shaft on other side.

Figure 9 Cavenderichthys talbragarensis. A, lateral view of the left mandible of MMF137a, drawn from Figure 21E. B, medial view of the right mandible of MMF13734a, drawn from Figure 21D. C, medial view of the left hyomandibular of MMF13734a, drawn from Figure 21B. D, lateral view of right hyomandibular of MMF13734a, drawn from Figure 21C. E, F, G, outlines of the hyomandibulars of Leptolepis normandica. H, I, Leptolepis coryphaenoides [Nybelin (1974) figure 3] included to provide a comparison with the structure of the hyomandibular of Cavenderichthys talbragarensis as seen above in $D$. The presence and location of the opercular process (pr.op) and the preopercular process (pr.pop) are very similar.

The retroarticular is a small bone, possibly fused to the posteroventral margin of the articular and forming part of the articulation of the lower jaw.

\section{Palatoquadrate arch}

The ectopterygoid, which can be seen on MMF36732a (Figure 6B) and MMF36732 (Figure $5 B)$, forms the anterior sidewall of the mouth. It is boomerang shaped, thin anteriorly and thickens posteriorly where it articulates with the quadrate.
The dorsal margin is convex while the ventral margin of the ectopterygoid is concave, does not articulate with anything and is usually covered by the upper jaw.

The quadrate can be seen on MMF36753a (Figure 6B), MMF36732a, ANU54962 and ANU54977 and is a fan shaped bone that forms part of the articulation with the mandible. The dorsal part is thin and spreads out like a quarter of a circle. The apex of the bone, which is ventral, thickens into an 
articulating post which articulates with the back of the angular-articular and the retroarticular process.

\section{Hyoid arch}

Of the hyoid arch, the hyomandibular bone is only rarely visible as it is generally covered by the preoperculum. In ANU54976 the dorsal end of the bone appears in the orbit, but in the dorso-ventrally flattened MMF13734a, both hyomandibulars are visible, see Figures 9C, 9D, and later in text the photographs of Figure 21. The bone is long with a central shaft, a thickened dorsal end and a thin expanded ventral end. The antero-dorsal margin projects anteriorly from the shaft, then curves smoothly to a dorsal point, resembling the shape of an axe head. The postero-dorsal margin curves concavely down to an opercular process. The postero-ventral margin thins out behind the base of the shaft into a thin flattened preopercular process with a curved margin. The ventral margin of this process extends in a straight diagonal line down to a point anterior of the shaft, and then curves back up to meet the shaft just below where the posterior part of the process intersects the shaft. The preopercular process is very thin and not likely to be preserved (or visible) in many cases. It is only due to the dorso-ventral flattening of just one specimen (MMF13734a) that the details of both the left and right hyomandibulars can be seen. A clearly visible foramen on the outer surface of the upper part of the bone allows passage of a branch of the facial nerve (Norden 1961), see Figures 9C, 9D.

It has not been possible to find sufficient evidence to describe the symplectic.

The epihyal, seen on ANU54976 (not figured), is usually covered by the preoperculum. It is a flat, roughly rectangular bone with a slightly concave anterior margin that articulates with the slightly convex posterior margin of the ceratohyal. The ventral margin is slightly convex. It appears to be associated with 3 or 4 spathiform branchiostegal rays.

The ceratohyal is often preserved and quite clearly visible, for example on MMF13555 (Figure 2B), MMF36732a (Figure 5B), MMF36761b (Figure 7B), MMF36732a peel (Figure 8B) and MMF36735 (not figured). The ends of the bone are flattened and splayed out with curved margins. The ventral margin is smoothly concave, and bears the attachments of the six thin branchiostegal rays. The dorsal margin also has a smooth, deep, sometimes semicircular curve. In this species the ceratohyal does not appear to generally be fenestrate. In several specimens (ANU54980, MMF36743, MMF13606a, MMF36721,) there may be a thin rod connecting the anterior and posterior dorsal margins, but in each case it has been broken. More commonly the ceratohyal resembles the shape of the archetypal dog's bone, e.g., MMF36732a (Figure 5B), MMF36753a (Figure 6A), MMF36761b (Figure 7B), MMF36781, MMF36743a and MMF36728. Cavender (1970) suggested that the rod-like connection between the dorsal ends of the ceratohyal may be present on the larger specimens. Many small specimens show that the ceratohyal is definitely not fenestrate (contra Arratia 1997) as the dorsal margins can be clearly seen and there is no sign of a rod connecting anterior to posterior.

Two very small hypohyal bones can be seen on MMF13555 (Figure 2B), MMF36732a (Figure 8B), MMF36729, and ANU54983, fitting into the slightly concave anterior surface of the ceratohyal. They occur one above the other, and would have been connected to the ceratohyal by cartilage. They appear as if they may be conical, with the upper one fitting over the apex of the lower one. Other forms of fish have only one hypohyal per ceratohyal, but in leptolepids, having two hypohyals is not uncommon. It is also the usual situation in modern Salmonidae.

\section{Branchial arches}

No observable articulated branchial arches have been preserved in these specimens, but isolated bones are identified below.

The urohyal is a very delicate median bone (see ANU54982, ANU54983 and MMF13603k) with a Yshape, where the branches are pointing posteriorly. The urohyal is located between the two sets of branchiostegal rays (MMF36732, Figure 5B and MMF36753a, Figure 6A). Its relationship with other bones, apart from the branchiostegal rays, cannot be determined.

The gular plate, which is seen on MMM36732a (Figures 6B, 8B), ANU54982 and ANU54983, is a small narrow median plate found between the two lower jaws. It is quite often visible with its anterior margin hidden behind the dentary, but its posterior margin pointing downwards. This is the case when the ceratohyal is also visible below the jaw-line. The gular plate has continuous growth lines outlining the elongated oval shape. It probably increases in length, but not greatly in width, as the individual grows.

\section{Vertebral column}

The number of centra is highly variable. Of the 48 peels with centra that can be counted reliably, there is a range from 35 to 45 centra (cf.43-45 recorded by Arratia 1997). The mean value is 40.4 with a standard deviation of 3.5 . There is also no relationship between length of the individual and number of centra. Each centrum is a thinly ossified cylinder, constricted in the middle. The centra in the abdominal region have a small process on each side for the attachment of the ribs.

The last two upturned centra in the tail are called 

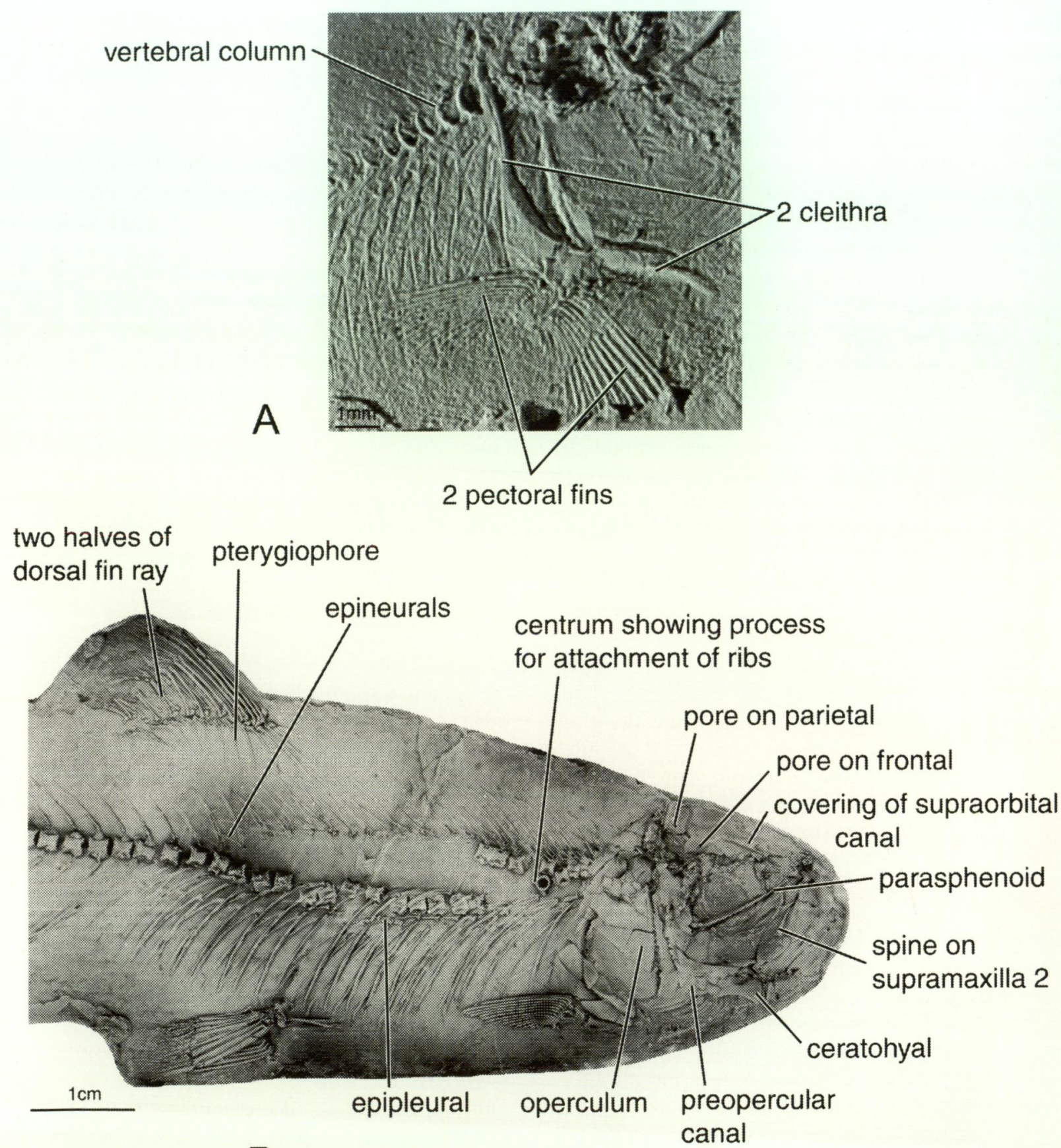

B

Figure 10 Cavenderichthys talbragarensis. A, pectoral fins of ANU54938, ventral view. B, peel of F27069 showing detail of the vertebral column. Vertebra turned on its side shows two small processes for the attachment of the ribs. Just ventral to the spine in the pleural region are small epipleural bones. The epineurals are visible detached from the dorsal side of the spine. On the pelvic fins distal branching of the rays can be seen.

ural centra. Anterior to this the centra that carry haemal arches are called preural centra.

Epineural bones come off the neural arches that carry ribs, anterior to the dorsal fin, see AMF27069 (Figure 10B), MMF36743b (Figure 16B), and AMAMF4133. They point backwards at an angle of about $20^{\circ}$ above the column. They occur on each side of the column because they are inter-muscular bones that support the flesh of the fish (Gosline 1971).

Anterior to the dorsal fin are interneural bones, which are "a series of median supporting rods" (Norden 1961: 689) extending from just below the dorsal surface of the fish to the level of the neural arches, see MMF36743b, AMF4133. They are thin rods whose proximal tips fit between the tips of the bifurcating neural arches (AMF51899, Figure 7A).

The neural arches are paired bones that articulate with the centra and form an arch through which the spinal cord passes. They extend dorsally approximately half way to the dorsal body margin. In the abdominal region it is often possible to see 
the two separate bones that form the arch, but behind the dorsal fin the bones of the neural arches are fused, forming neural spines. They are well ossified.

The haemal arches (ANU54970, Figure 16A) are composed of a pair of bones that fuse together to form haemal spines. The junction of the ural and preural centra is marked when the haemal artery is no longer passing through a haemal arch.

The number of ribs is variable as is the number of centra. Of the 49 specimens where ribs can be counted, the mean number is 23 with a standard deviation of 2.3. The range is from 20 to 26 pairs of ribs.

In a couple of specimens there appear to be epipleurals (AMF27069, Figure 10B), which are small fine bony projections originating near the point of attachment of the ribs and extending backwards to the level of the next rib. This has only been seen in the pleural region. Arratia (1997) stated that Cavenderichthys lacks epipleurals.
Caudal fin

The caudal centra are 3 upturned vertebrae in the caudal region, comprising preural centrum 1 and the ural centra, which is a characteristic of coregonines, salmonines, and thymallines (Norden 1961). The preural centra are well ossified, each consisting of a ring with a large circular canal in the middle. The haemal and neural arches always appear to be attached to the centra. The first preural centrum is slightly smaller than the subsequent ones. The first ural centrum appears to be fused with the second, as it is longer than other centra but has a smaller diameter. The first and second hypurals, which articulate with U1-2, appear to be fused, or at least closely associated.

The principal rays of the caudal fin form a double series of rays, which sandwich the ends of the hypurals, to which they are attached (Figure 12C). The two outer principal rays are segmented, but do not divide. The inner rays branch progressively earlier toward the centre of the tail. As the rays
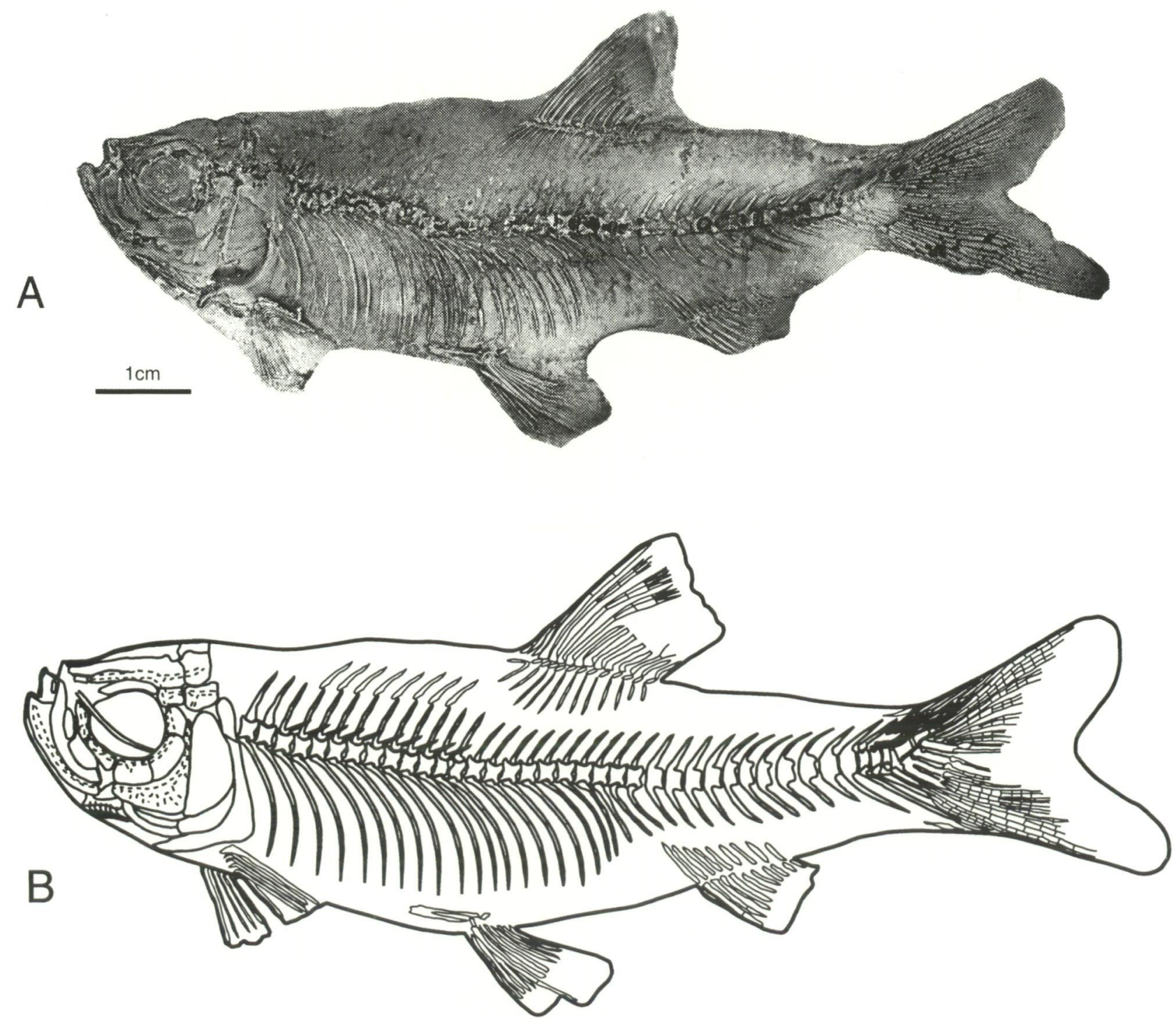

Figure 11 Cavenderichthys talbragarensis. A, F4133 used for the reconstruction of the skeleton of the whole fish in B. 

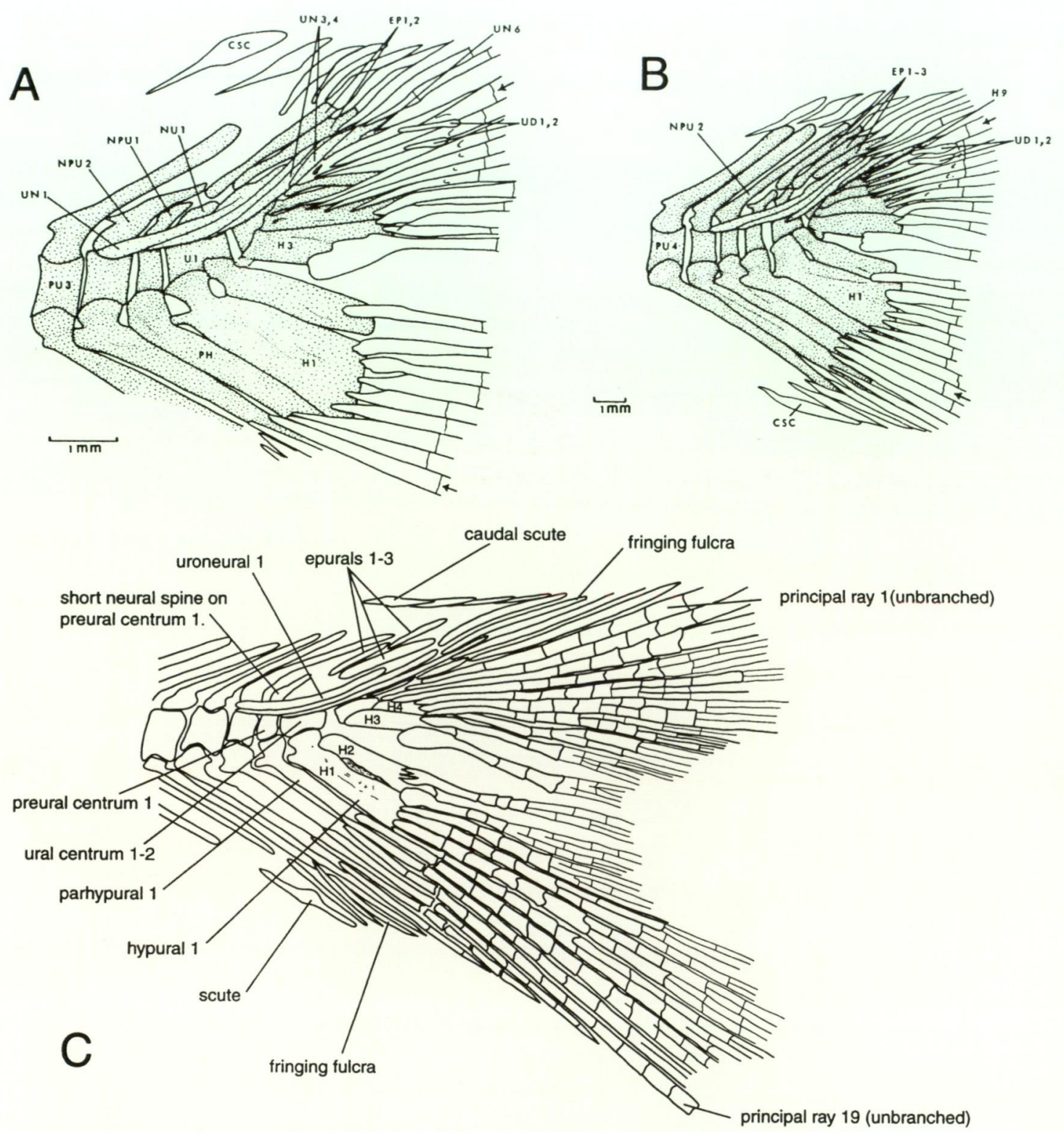

Figure 12 Cavenderichthys talbragarensis. Comparison of reconstructions of the caudal skeleton. A, Patterson and Rosen (1977) figure 46 reconstructed from BMNH P37973. B, Patterson and Rosen (1977) figure 46 reconstructed from BMNH P12439. C, my reconstruction of MMF13561a, showing species defining similarities, but some small inter-species variation.

branch they become more and more delicate, so the complete fin is preserved in relatively few specimens. They branch up to four times, such that the middle section of the tail, where branching occurs early, is very thin, delicate and flexible. The principal rays articulate with the hypurals in the upper section, and in the lower section PR 19 articulates with pre-hypural haemal spine 2 (parhypurals), PRs 18 and 17 articulate with prehypural haemal spine 1, then PRs 16, 15, 14, 13 and 12 articulate with hypural 1-2 (combined unit), and PR 11 articulates with hypural 3 . The proximal ends of several PRs are broad where they articulate with the hypurals, e.g., on MMF36746 (Figure 14A) the ends of PRs 8, 9 and 10 are enlarged. In contrast, the proximal ends of PRs 1-6 taper to a point.
The neural spines on the preural centra are narrower than the haemal spines. They also become progressively shorter posteriorly. The neural spines on preural centra 2, 3 and 4 bend back strongly, and they overlie the short neural spine on preural centrum 1 .

There are three epurals, rarely four, which extend from the ends of the long neural spines to the bottom of the basal fulcra, covering the dorsal surface between the caudal scute and the first principal ray (Figure 12C and MMF36773, Figure 13B).

Dorsal to the epurals lie the epaxial basal fulcra (MMF36773, Figure 13B), usually about six, which form a series with the three procurrent rays between the principal rays and the anterior caudal scute. Sometimes it is not easy to distinguish 

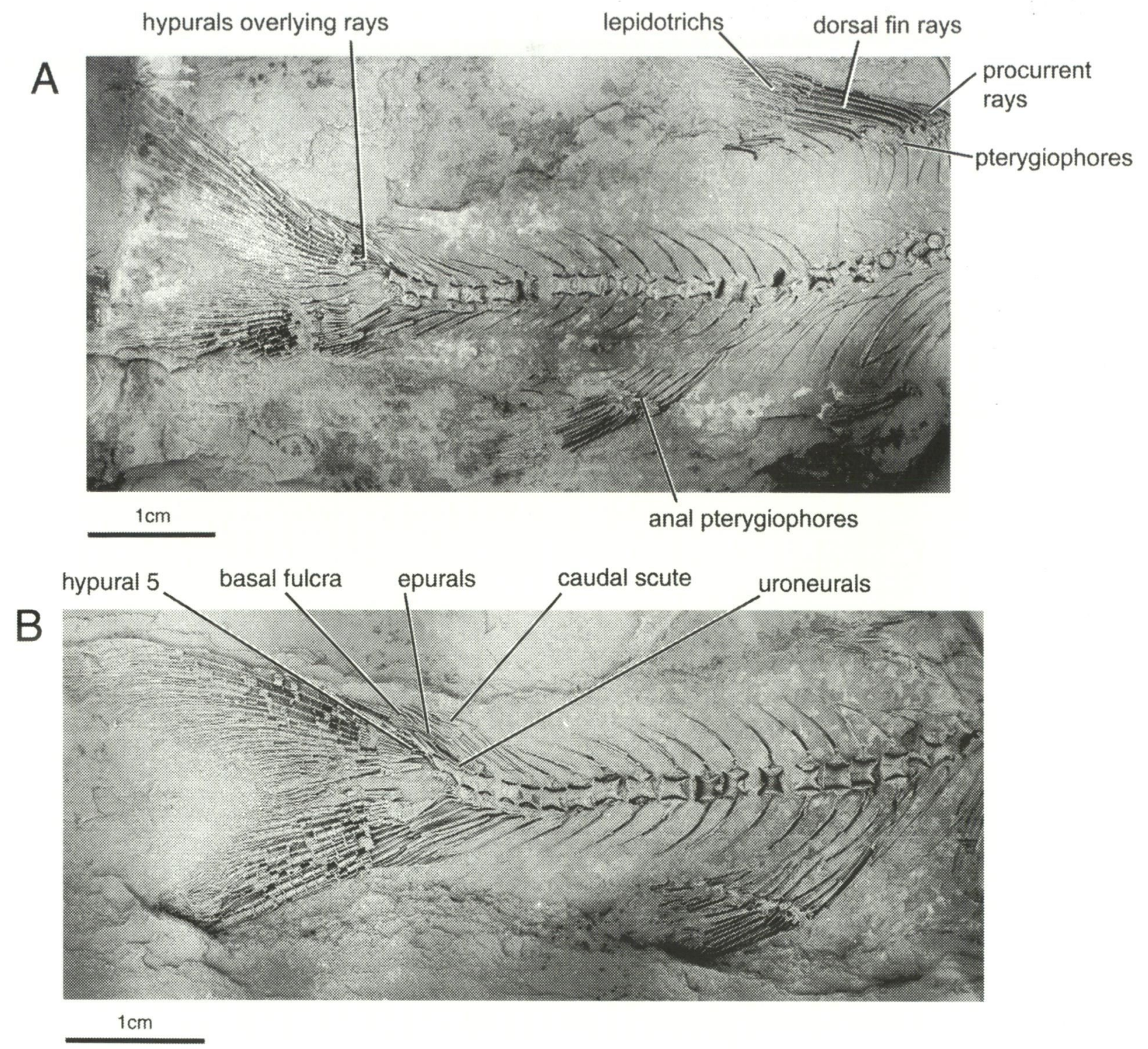

Figure 13 Cavenderichthys talbragarensis. Photographs of the original specimens showing the layered nature of the caudal skeleton. Peels were not made due to the risk of destroying some of the delicate overlying structures, especially where the hypurals overlie the rays. A, MMF36718. B, MMF36773.

between the basal fulcra and the unsegmented procurrent rays. There are also several ventral basal fulcra.

The caudal scute marks the junction between the dorsal surface of the fish and its tail (Figure 12C and MMF36773, Figure 13B). It is similar in size to the six dorsal basal fulcra, but slightly sinuous in shape, and broader. The ventral caudal scute is similarly a sinuously shaped bone.

Generally there are three uroneurals that lie down either side of the ural centra. They act as bracing for the thinning end of the vertebral column. They project anteriorly beyond ural centrum 1 and overlap preural centrum 1 and 2, effectively crossing the "chondrostean hinge". Usually one, sometimes two more, short uroneurals project backwards from the posterior of ural centrum 1-2.
These five uroneurals make a functional continuous series from the epurals through uroneurals to the principal rays in the upper lobe. These can be seen on MMF36773 (Figure 13B), MMF36746 (Figure 14A), MMF36732a (Figure 15B), and ANU54975 (Figure 15A).

There are seven hypurals (MMF13561a, Figure 12C). The lowest two hypurals articulate with the first ural centrum 1-2. They often appear to be fused. Hypural 3, which articulates with ural centrum 3, carries the inner rays of the upper lobe, i.e. principal rays 8,9 , and 10 . These rays often have thickened ends where they attach to the hypural. This probably gives strength to the fragile but flexible inner rays. In most cases the upper four, or possibly five, hypurals are covered by the overlapping ends of the upper principal rays. 


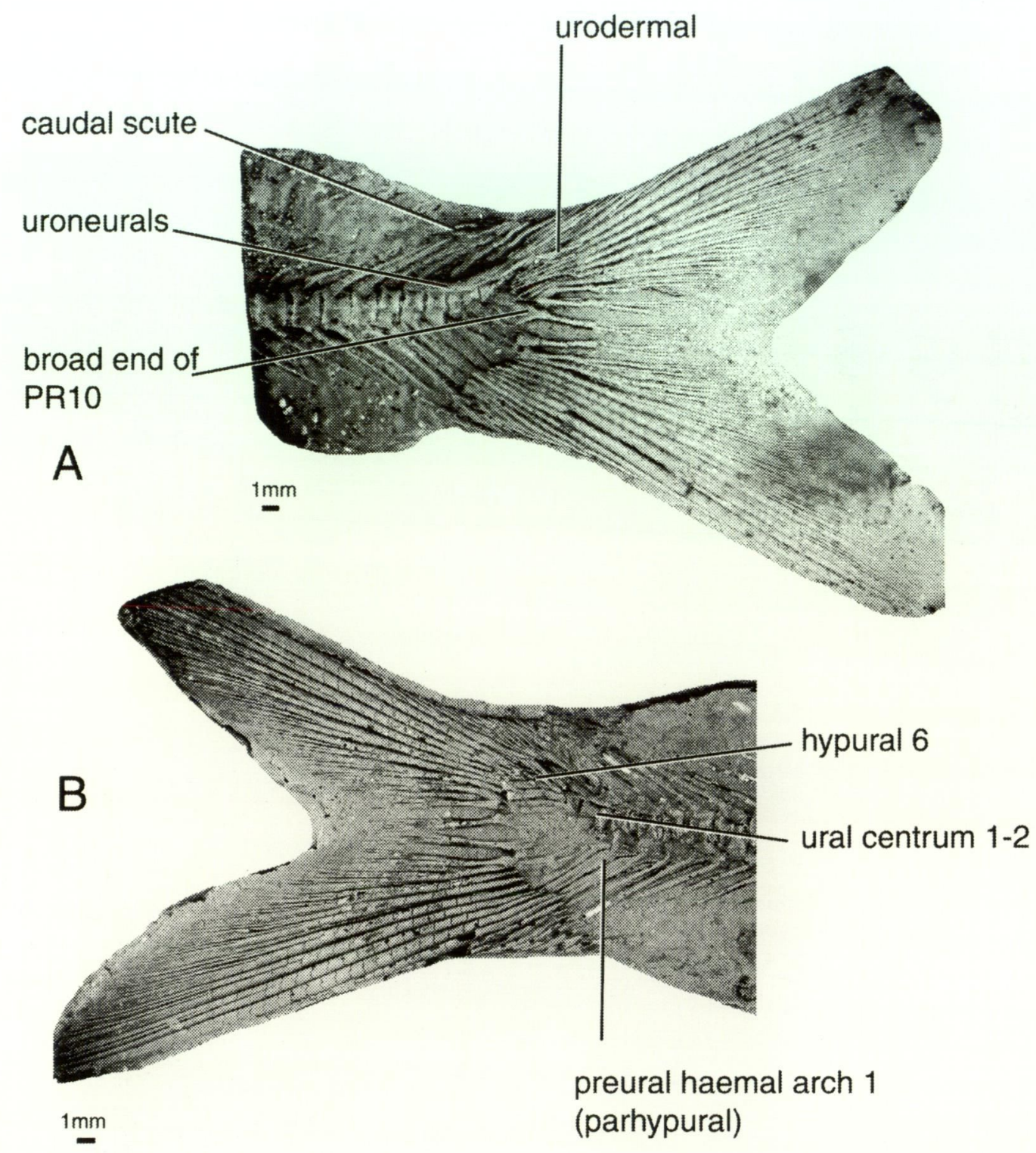

Figure 14 Cavenderichthys talbragarensis. These photographs of peels support the caudal skeleton reconstruction in Figure 12 C. A, MMF36746. B, MMF36748.

Urodermal bones are not generally preserved. However in three specimens, AMF4133, MMF13569 and ANU54975 (Figure 15A), there appear to be two small fine bones that are not part of the segmented principal rays in the dorsal part of the fin. They overlap two principal rays, either 2 and 3 or 3 and 4 , and may provide extra bracing at the end of the vertebral column. According to Cavender (1970), "they are clearly ossifications at the distal ends of two of the tendons that originate from the superficial epaxial muscle mass in the caudal region and which insert proximally on the dorsal edges of the first and second branched rays respectively." Maybe they are not always ossified, or possibly they are not always preserved because they lie outside the general caudal fin structure (see also MMF36746, Figure 14A).

\section{Median fins}

The dorsal fin is positioned over the mid point of the body, see AMF27069 (Figure 10B), MMAMF4133, ANU54946 and MMF36743. The anterior margin of the dorsal fin is about level with the mid-point of the vertebral column. The posterior margin is level with the anterior margin of the anal fin. The length of the fin, measured along the line of the articulation, is $10-12 \mathrm{~mm}$. This position in the mid-portion of the fish indicates a role as keel (Gosline 1971).

The dorsal fin consists of 12 to 15 rays, the anterior three being short procurrent rays that do not branch, the first principal ray being full length and unbranched, and the rest being full-length rays that branch into lepidotrichs about halfway along their length. The rays are supported by internal 

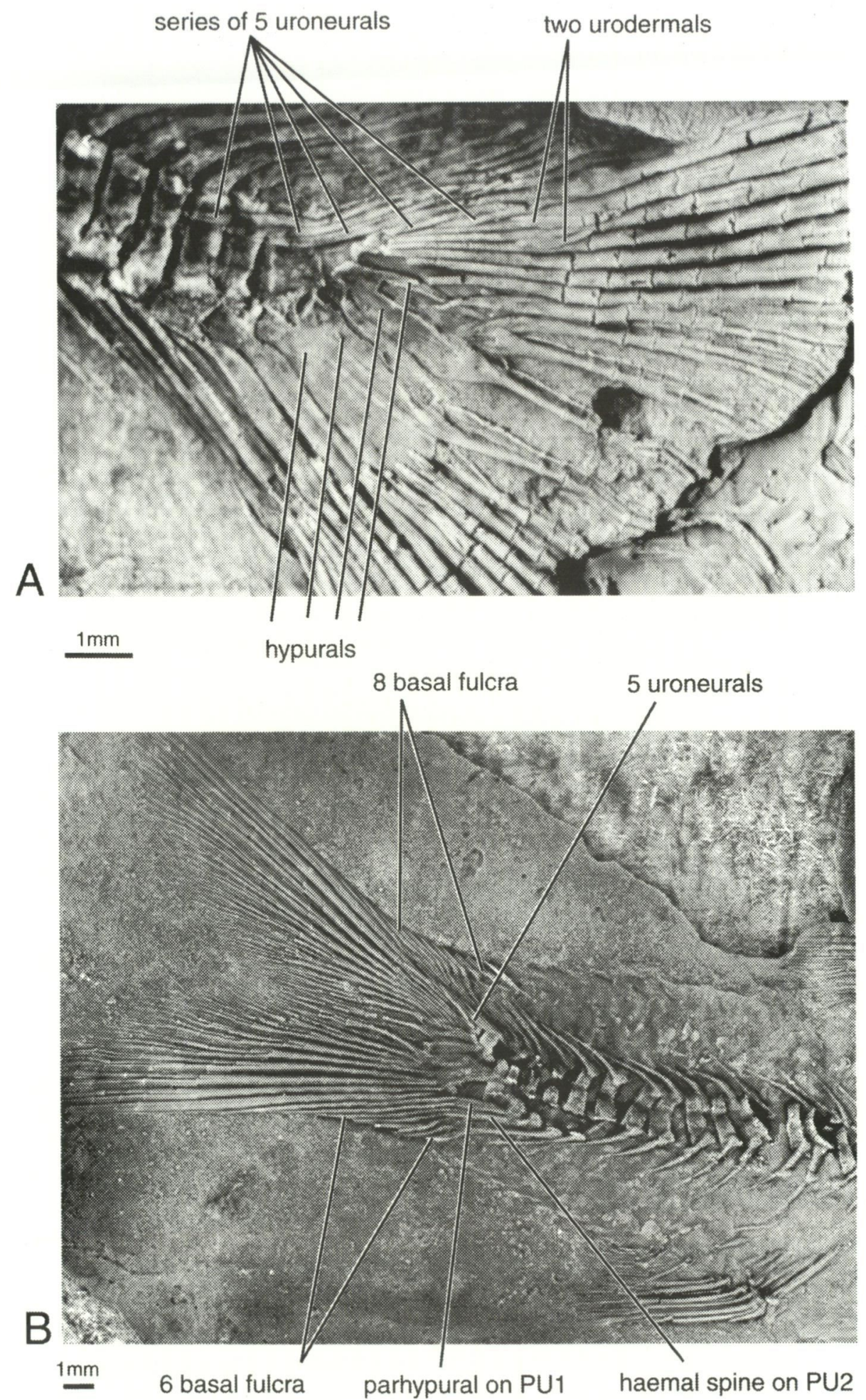

Figure 15 Cavenderichthys talbragarensis. A, the peel of ANU54975 shows two urodermals and the series of uroneurals. B, on MMF36732a the dorsal and ventral basal fulcra are clearly preserved.

bones called pterygiophores (MMF36718, Figure $13 \mathrm{~A})$, also called radials, which are described by Norden (1961) as being "composed of 3 segments, a small, rounded distal bone, a short, horizontal middle bone and a long, pointed proximal bone." It is possible to see both the proximal and horizontal pterygiophores in AMF27069 (Figure 10B). The anterior proximal pterygiophore points forward, lying at an acute angle to the dorsal surface, and is forked. It supports the anterior procurrent rays. The pterygiophores supporting the middle of the fin are perpendicular to the dorsal surface. They are fine, pointed rods, but they broaden dorsally where they articulate with the horizontal elements. The pterygiophores are single structures, which appear in the mid-line, dorsal to the neural arches.

The fin rays of the dorsal fin, like the pterygiophores, are fine, emerging from the broader 

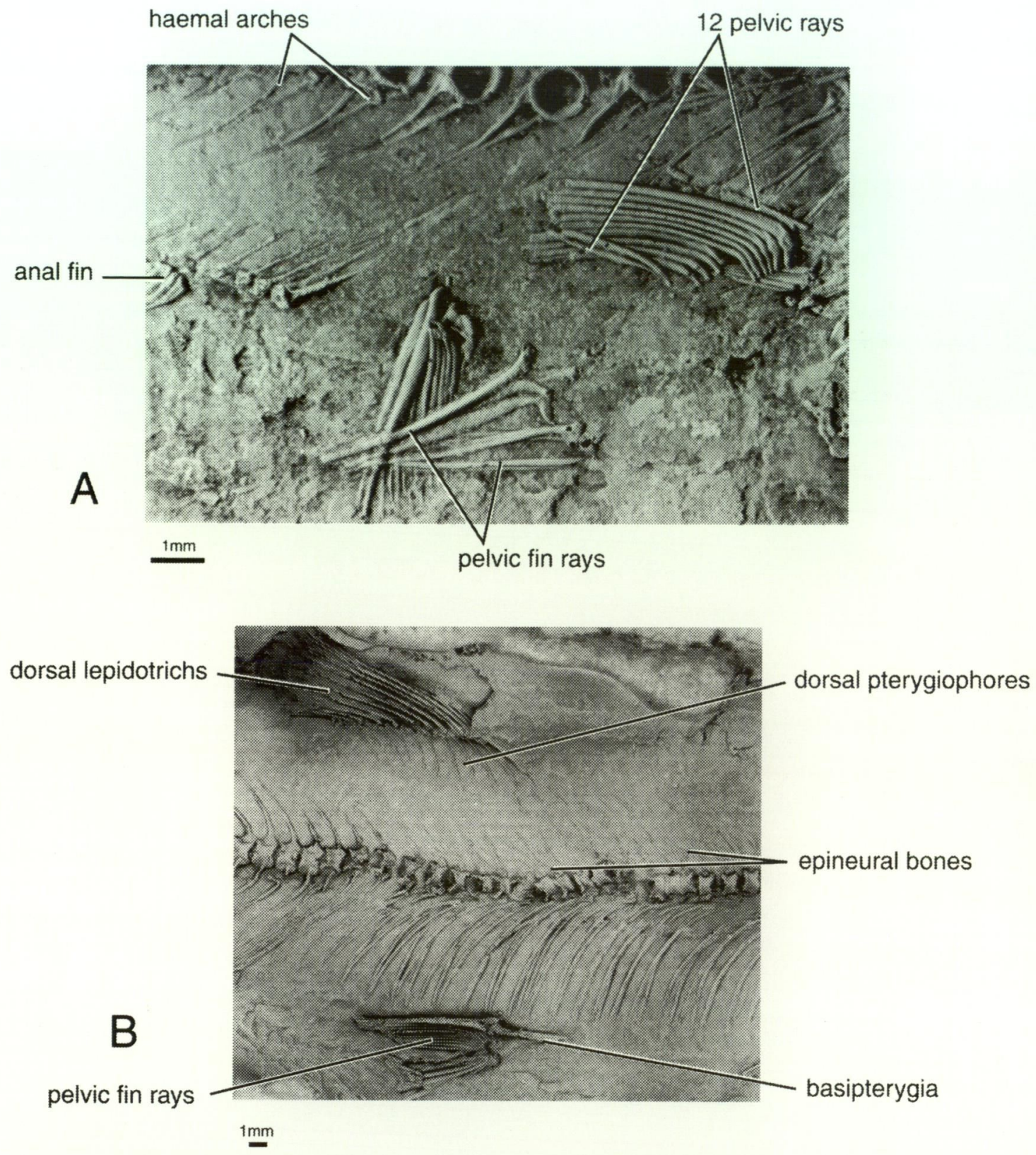

Figure 16 Cavenderichthys talbragarensis. Pelvic fins. A, in this detail of ANU54970 12 pelvic fin rays can be seen, and the structure of the hemal arches. B, on MMF36743b the pelvic fin is in situ, directly under the position of the dorsal fin.

ball-like articulating surface that fits over the middle horizontal pterygiophore. They are composed of two half cylinders which are held tightly together along their length. The rays gradually expand slightly along their length until they bifurcate about half way along the total length of the fin. Beyond this bifurcation, the lepidotrichs are jointed, and bifurcate once more, so that at the back of the fin there are four lepidotrichs for every ray.

The anal fin is located half way between the pelvic fins and the caudal fin, see Figure $11 \mathrm{~A}$ and $\mathrm{B}$ and MMF36737, MMF36743b (unfigured). Its anterior margin is level with the posterior margin of the dorsal fin. It is always supported by nine pterygiophores, or radials, which are single bones.
They are narrow bones that broaden toward the proximal end. The ten anal fin rays are paired bones that broaden where they articulate with the pterygiophores. With the exception of PR1, which is unbranched, the principal rays also branch into lepidotrichs, which are sometimes preserved, resulting in four lepidotrichs for every original ray. A short unbranched ray is at the anterior margin of the anal fin.

\section{Pectoral girdle}

The post-temporal is often not preserved. It has been seen as a squarish bone that comprises the area between the extrascapulars and the scales (Figure $7 \mathrm{~A})$. It carries the lateral line canal onto the head, 
and in 551799 (not figured) it appears to have a canal running diagonally across the bone. The bone is posterior to the extrascapulars, and dorsal to the supracleithrum.

The supracleithrum is the dorsal bone of the pectoral girdle (Figure $6 \mathrm{~A}$ ). It is a narrow bone that, when fossilized, crosses the position where the vertebral column emerges from the back of the braincase. The dorsal margin is rounded, while the ventral margin abuts or slightly overlaps the top of the cleithrum

The cleithrum (Figures 6A, 10A) is the largest bone of the pectoral girdle. It extends from just below the level of the vertebral column in a curve, to end at the level of the branchiostegal rays. The bone is quite deep, having a strong ridge on the external surface. The bottom of the operculum and suboperculum are sometimes crushed over the cleithrum, making a deep hollow and a high ridge at the postero-ventral margin of the head.

In the 25 specimens examined for the pectoral girdle no bone could be described as a postcleithrum.

The scapula is a short stout bone that articulates with the coracoid anteriorly and with the first principal ray of the pectoral fin posteriorly. It is often covered by the ventral margin of the cleithrum.

The coracoid occurs at the antero-ventral margin of the cleithrum. It appears to be a flattish bone, slightly pointed anteriorly and broader posteriorly, which articulates with the cleithrum and the scapula. The articulation with the cleithrum has not been observed clearly, although the coracoid bone is always adjacent to the cleithrum. The articulation with the scapula can be seen in specimen ANU54940 (not figured).

\section{Pectoral fins}

There are 12 rays in each of the pectoral fins (Figures 6A, 7B, 8B, 10A). The first ray is more robust than the others and has a broad head that articulates directly with the scapula. The other 11 rays are bent over nearly at right angles at the proximal ends where they form delicate points to enable them to articulate with the three radials. The radials are two or three short straight rods that start near the scapula and extend just far enough to allow the rays to articulate with them. The direction of the radials is the same as the direction of the rays, which explains why the rays have to turn at right angles to be able to attach to the radials. The radials are visible in specimen MMF36758a, but are generally not preserved. The rays themselves are unsegmented for about half their length, after which they become segmented then divide into lepidotrichs. The two pectoral fins originate very close together on the ventral margin of the body, just behind the head. This position is much lower than some more recent fish, but is similar to other leptolepids.

\section{Pelvic girdle}

Norden (1961) described the basipterygia as "a pair of triangular endochondral bones which form the pelvic girdle." In Cavenderichthys talbragarensis, each basipterygium seems to widen posteriorly where it articulates with the rays of the pelvic fins (Figure 16B).

Each pelvic fin has 12 rays (Figure 16A). They also turn around at right angles at the proximal end. The rays are unsegmented for the first half of their length, then they become segmented and also divide into lepidotrichs.

Scales are cycloid with concentric growth rings. They are generally only visible near dorsal and ventral body margins, their delicate nature, combined with the well ossified spinal structures, leading to their poor preservation.

\section{DISCUSSION}

\section{The early work}

Woodward (1895) classified the most common fish in the Talbragar assemblage as a member of the Family Leptolepididae, genus Leptolepis. He noted its general characteristics, but commented that no detailed osteological synopsis had been published for the genus. He described many of the features already listed in this paper, such as the narrow roof of skull between the eyes, the wavy suture separating the frontals, the small parietals, the minute premaxilla, and the two elongated supramaxillary bones. He did say that the sclerotic ring is ossified, but this has only been observed in ANU54956 (Figure 2A) and MMF13555 (Figure 2B). In the majority of specimens there is no evidence for a sclerotic ring. He did not describe a gular plate, but it has been now observed in 20 specimens. When describing the ceratohyal he said it has "the ordinary hour-glass form, but is noteworthy for the extension of a supplementary, delicate, straight rod of bone between its extremities on the upper side." (Woodward 1895: 20) This comment is very similar to the description in this paper, and less aligned with the comment by Arratia that the ceratohyal is always fenestrate (Arratia 1997: 19).

Woodward (1895) also described three species of Leptolepis: L. talbragarensis, L. lowei and L. gregarius. Leptolepis talbragarensis is by far the most common species. Wade (1941:83) wrote "Previously three species have been ascribed to the genus from this locality, but in the view of the uniformity of the structure of the head the writer is convinced that only one species, Leptolepis talbragarensis, need be recognised, the specific differences previously relied on being due to individual peculiarities or 
mode of preservation or differences in maturity." Further examination during the current study of the bones of $L$. gregarius demonstrates it is just a schooling, juvenile form of talbragarensis. Woodward describes $L$. gregarius as having a different proportion of the head, and the anal fin being slightly more anterior, but these characteristics are not supported by a statistical analysis of the dimensions. The two specimens called $L$. lowei are slightly more elongated in the head region than $L$. talbragarensis, but the rest of the skeleton, including the tail, is the same as talbragarensis. It is here considered that they belong to the same species, but are differently preserved.

Wade (1941) did not add any detail to the description of Leptolepis talbragarensis, but he did reclassify the other genera present in the assemblage. Cavender (1970) used Leptolepis? talbragarensis as an example of an early teleost and compared it with genera from the coregonines and other salmonids. His description of $L$ ? talbragarensis is quite detailed and it has been the reference description for subsequent workers including Arratia (1997), but it formed part of a comparison and was not a systematic description.

Nybelin (1974) reassessed the classification of $L$. talbragarensis noting that it possesses some characteristics "unfamiliar in the true leptolepids. The deep body and the configuration of the head with its short snout are rather unlike the leptolepids. The anterior part of the frontal, anterior to the exit of the supraorbital sensory canal, is strikingly short, much shorter than in the leptolepids, and seemingly ending at the same level as the nasal."(Nybelin 1974: 170) The description of the body as deep is very imprecise, and when compared with truly deep-bodied fish such as Aethiolepis mirabilis it is seen as being totally inappropriate. Both Arratia (1997) and Cavender (1970) continued the pattern of describing Cavenderichthys talbragarensis as deep bodied, but such a description is misleading, as even the adults are fusiform. The vast majority of examples are small, thin, fusiform fish, with the dorsal and ventral margins being approximately parallel. The fish has a short snout with a protruding lower jaw, a centrally placed short dorsal fin, pectoral fins that are placed low, a centrally placed low pair of pelvic fins, short anal fin positioned just posterior to level of dorsal fin, and a delicate, symmetrical, bifurcated tail.

Nybelin (1974) considered the most significant osteological features of the true leptolepids are the presence of a preopercular process on the hyomandibular and the notch in the ascending anterior margin of the dentary. Neither he nor Cavender (1970) saw these features on $L$. talbragarensis. Nybelin (1974) considered that the most significant difference between $L$. talbragarensis and the true leptolepids is in the sensory canal system - few branches from the infraorbital sensory canal, and the 6 branches on the preopercular canal is smaller than the number of branches in other leptolepids. There are similarities between $L$. talbragarensis and Leptolepides sprattiformis, but the differences in the caudal skeleton were considered to be the most striking difference. "The presence of four epurals, only a single neural arch on U1, all uroneurals mutually free, and two urodermals, separate talbragarensis and sprattiformis to such a degree that a close relationship between them seems definitely excluded." (Nybelin 1974: 171) Thus the species "L." talbragarensis was removed from the family Leptolepididae.

\section{Points of Contention in Understanding the Morphology}

The illustrations of Cavenderichthys talbragarensis by Arratia (1997) are refinements of those published by Cavender (1970), and I agree with the changes she has made to his description by including a gular plate and an interoperculum. Arratia maintained the pattern developed by Nybelin (1974) and endorsed by Patterson (Patterson and Rosen 1977) of there being no connection between the suborbital canal and the supraorbital canal (contra Cavender 1970). This interpretation is disputed for several reasons. Firstly, this part of the skull is notoriously poorly preserved, and few specimens show clear identification of the dermosphenotic. Secondly, the branch of the supraorbital canal that heads ventrally on the frontal seems to be headed directly for the position where the dermosphenotic ought to be in most specimens. Thirdly, in modern teleosts the connection between the supraorbital canal and the suborbital canal is the normal condition. In no specimen in which both canals are visible, are they not connected.

Arratia (1997) stated that the ceratohyal is always fenestrate, whereas many specimens studied herein show no sign of a connection between the dorsal projections of the ends of the ceratohyal, neither bone nor cartilage. However, there are also several examples showing evidence of such a connection, such as ANU 54980 and ANU 54976, which have an incomplete link across the dorsal margin of the bone. Thus I presume it is possible for this bone to be fenestrate, as is the common condition in related species, but it is definitely not present in all samples.

Observations of the hyomandibular and the dentary in the dorso-ventrally flattened specimen (MMF13734a) suggest that $C$. talbragarensis does have a preopercular process on the hyomandibular and also has a significant dent on the rising anterior surface of the dentary that corresponds with the 
leptolepid notch. The lack of these two characters has been considered significant by other workers, and led Nybelin (1974) to argue that C. talbragarensis could not be a member of the family Leptolepididae. The absence of a suborbital bone, which is present in the genus Leptolepis but not in later leptolepids, is here considered more significant than the absence of a small process on one bone. On the basis that it has been found that Cavenderichthys talbragarensis does have these characteristics, it is now felt that it should be included in the family Leptolepididae.

Description of the caudal skeleton largely agrees with the illustrations provided by Arratia. She showed the intra-species variation in the number of epurals (three and four), and uroneurals (six and seven), but the eighth hypural is doubtful (only seven hypurals have been observed in this study).

The dorsal fin has a range of the number of fin rays and pterygiophores. Considering fin rays, five specimens have 10 principal rays, four have 11 , six have 12, and one has 13. Considering pterygiophores, one has 10 , one has 11, twelve have 12, and two have 13. Many specimens do not have all rays readily visible. Arratia's diagnosis of Cavenderichthys noted 15 dorsal rays, corresponding to 12 principal rays plus three unsegmented rays. This is certainly the most common case in my specimens, but not the only possibility.

The numbers of rays in the fins agree with other descriptions, but wide variation is found in the number of vertebrae (range 34 to 45 centra, excluding the last two ural centra). The number of vertebrae is not related to the length of the specimen, but it is closely related to the number of pairs of ribs. Thus there is variation both within the abdominal vertebrae and the precaudal vertebrae.

An analysis was made of the structure of the dorsal fin. The angle of elevation of the dorsal fins can vary from $70^{\circ}$ to $15^{\circ}$, without any sign of disarticulation or destruction of the joints. Of 43 specimens for which dorsal fins were measured, three had an angle of elevation of $>60^{\circ}, 25$ were between $60^{\circ}$ and $30^{\circ}$, while 15 were collapsed to less than $30^{\circ}$. This indicates that the fin could be collapsed when travelling fast, and raised like a keel when cornering. According to Gosline (1971) this is a characteristic of teleosts, that "the whole fin can be raised or lowered, more or less like a partially collapsible fan. The soft rays may also be swung from side to side by the contraction of muscles attached to the base." (Gosline 1971: 23). The size of the fin is comparatively small and takes up less than $1 / 5$ the total length of the fish.

Arratia (1997: 19) argued that C. talbragarensis is a "deep-bodied" fish. In order to test this, measurements were made of its depth to establish the ratio of depth to length. The ratio of the average depth to average length is about 1:4.8. The results are summarised in the following graph (Figure 17). The straight-line relationship between length and depth suggests that it is determined only by the stage of growth. The graph is based on data from 86 specimens. The regression equation is $y=0.25 x-0.3$.

\section{Length vs depth}

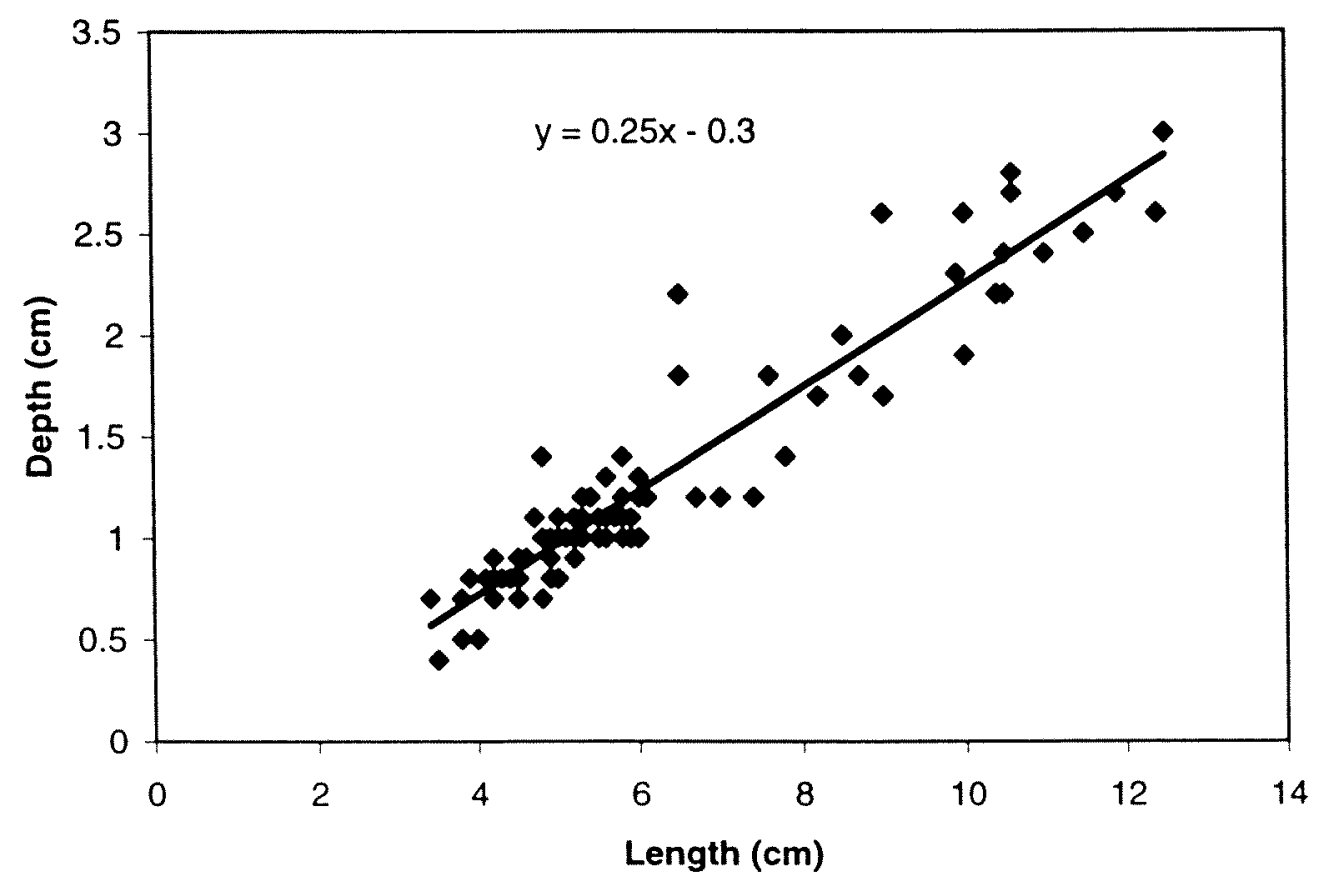

Figure 17 Graph of relationship between length and depth. 
The concentration of data in the lower left hand corner represents the large number of small specimens collected on the slabs representing the mass kill. The smaller number of larger fish is due to at least two factors. Firstly fewer individuals survive to be fossilised in their maturity. These individuals occur singularly rather than on mass kill slabs. The other factor is related to the habits of collectors. Large, well-preserved specimens are well regarded in collections, so isolated examples of medium sized fish may be overlooked when faced with the prolific numbers of small individuals on large slabs, and the few excellent large specimens. Thus the distribution on the graph does not necessarily represent the natural distribution in the population.

\section{Comparisons between Cavenderichthys and Leptolepis}

\section{The Head}

The type species of Leptolepis, which is Leptolepis coryphaenoides, and $L$. normandica described by Nybelin (1974), have several significant differences from C. talbragarensis, as well as the obvious similarities (see Figure 18). The head of $C$. talbragarensis is shorter that $L$. normandica and $L$. coryphaenoides. Nybelin (1974) suggested that this might be due to the shortness of the frontal bones, but Nybelin's figures 1 and 4 (Figure 18A, 18B) show the rostral is the bone that is significantly shorter in C. talbragarensis. Also in these text figures there is a large gap behind the upper jaw, resulting from the large size of the infraorbital 3 bone, which in both $L$. coryphaenoides and $L$. normandica is considerably wider than the other bones in the infraorbital series. In C. talbragarensis the posterior infraorbitals are all about the same width, allowing the preopercular to come closer to the orbit. This arrangement is very similar to Tharsis dubius, an Upper Jurassic (Kimmeridgian) member of the Family Leptolepididae (Figure 18D). The other significant difference is that $C$. talbragarensis lacks a suborbital bone between the infraorbital series and the preoperculum, and once again this is a point of similarity with $T$. dubius. This is also tied in with the consistent width of the posterior infraorbital bones, leading to an overall shortening of the head in comparison with L. normandica. In C. talbragarensis the size of the orbit is relatively large, which means that the dermal bones occupy a restricted space, even if the underlying structures of the braincase are very similar in size to other species.

Nybelin (1974) placed a great deal of emphasis for classification on the sensory canal systems, especially on the preoperculum and the infraorbital series. C. talbragarensis certainly has fewer branches on both these canal systems. Considering the preopercular canal, C. talbragarensis has a maximum of six undivided branches of this canal. This is far less than $L$. coryphaenoides (19), and less than $L$. normandica (10), but quite similar to Leptolepides sprattiformis (5). The latter (Figure 18C) also has a very similar jaw arrangement to $C$. talbragarensis. The suborbital canal system on C. talbragarensis has very few branches, possibly a few on the lachrymal, definitely one on the infraorbital, but none or very few on the postorbitals. This is very different to $L$. coryphaenoides, but quite similar to Leptolepides sprattiformis.

The supraorbital sensory canal in $C$. talbragarensis also has very few branches. However, Nybelin's (1974) figures $1 \mathrm{~B}$ and $4 \mathrm{~B}$ show that on $L$. coryphaenoides and $C$. talbragarensis (Figure 18A, $18 \mathrm{~B}$ ) the presence of pores along the canal is similar. There may be more pores present on $C$. talbragarensis than figured herein, but they are not always consistently placed. The back of the skull is not included in the diagram because it has not been possible to clarify the arrangement of extrascapulars and suprascapulars due to poor preservation. The presence of a branch in the supraorbital canal just above the position of the dermosphenotic is likely since the posterior branch of the canal terminates in the parietal, as shown by Nybelin (1974), and thus the ventrally directed branch should be connected to the infraorbital canal on the dermosphenotic. This is the logical connection, as the lateral line canal system has to be interlinked, and it is the general situation in similar extant forms. Possibly there is no connection between these canals in members of the Leptolepididae, as figured by Nybelin (1974), or possibly it is present but has just not been observed or described.

Comparison of the text-figures from Nybelin (1974) and those from Patterson and Rosen (1977) with the new reconstruction of the head of $C$. talbragarensis indicates that the parasphenoid is a valid point of comparison. Nybelin did not draw the parasphenoid on either $L$. normandica or $L$. coryphaenoides (his figures 1 and 4), however the photographs in his plate 2 figure 2 and plate 4 figure 2 (L. normandica) and plate 6 figure 1, plate 7 figure 1 and plate 9 figure 4 (L. coryphaenoides) the parasphenoid is quite clearly visible. This omission in the drawings may have led to some confusion because Patterson and Rosen (1977) have included the parasphenoid in diagrams of Leptolepides sprattiformis and Tharsis dubius. It is certainly an obvious characteristic of $C$. talbragarensis as it bisects the orbit, thus comparing very closely with these other species.

The operculum in C. talbragarensis is narrower at the top with its anterior and posterior margins diverging ventrally to form an approximately triangular shape, whereas in $L$. coryphaenoides the anterior and posterior margins are almost parallel.

The skull roof is another region that requires 

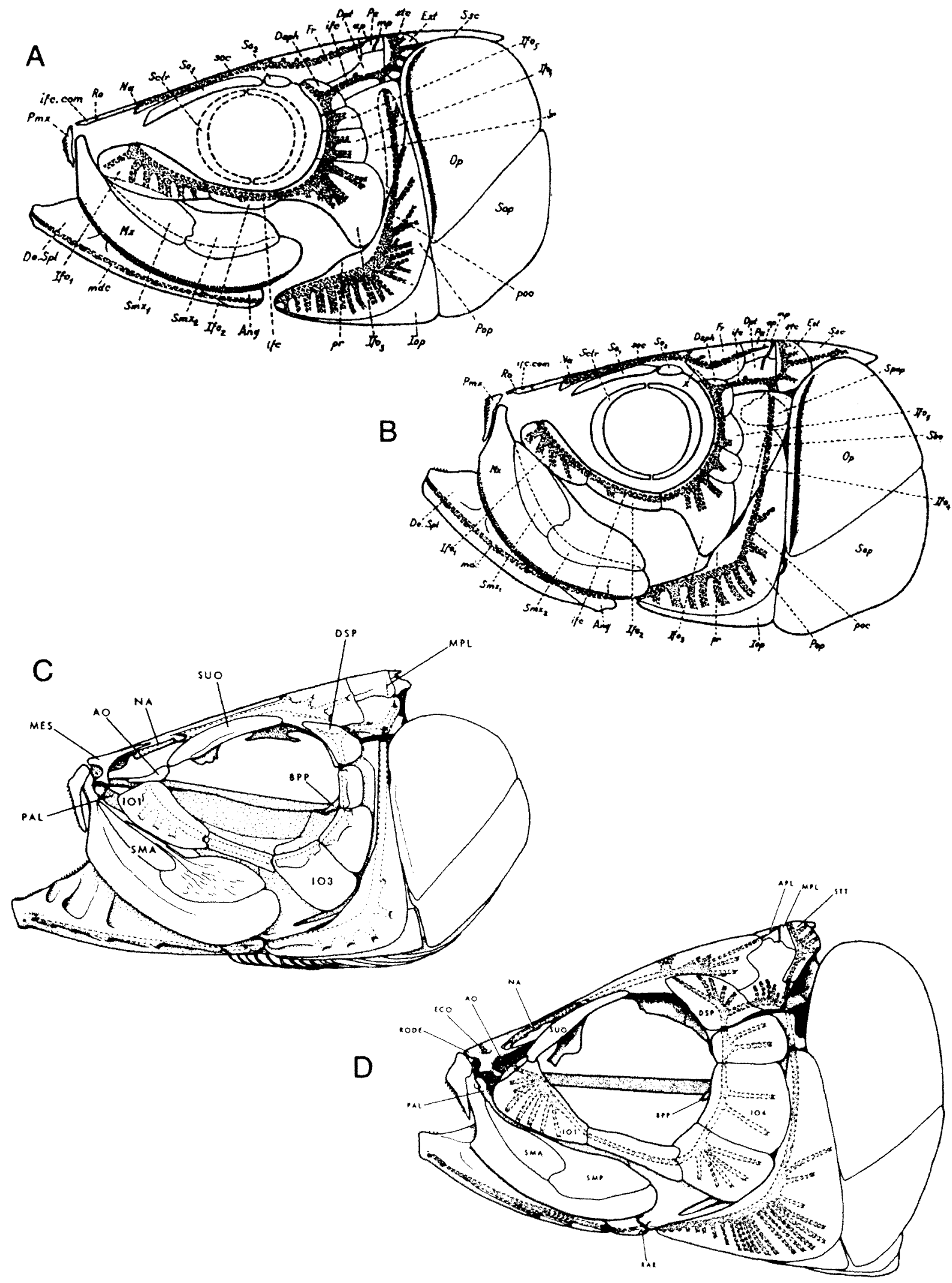

Figure 18 Comparative reconstructions of heads. A, Leptolepis normandica from Nybelin (1974, text fig. 1A). B. Leptolepis coryphaenoides from Nybelin (1974, figure 4A). C, Leptolepides sprattiformis from Patterson and Rosen (1977, figure 49). D, Tharsis dubius from Patterson and Rosen (1977, figure 34). 

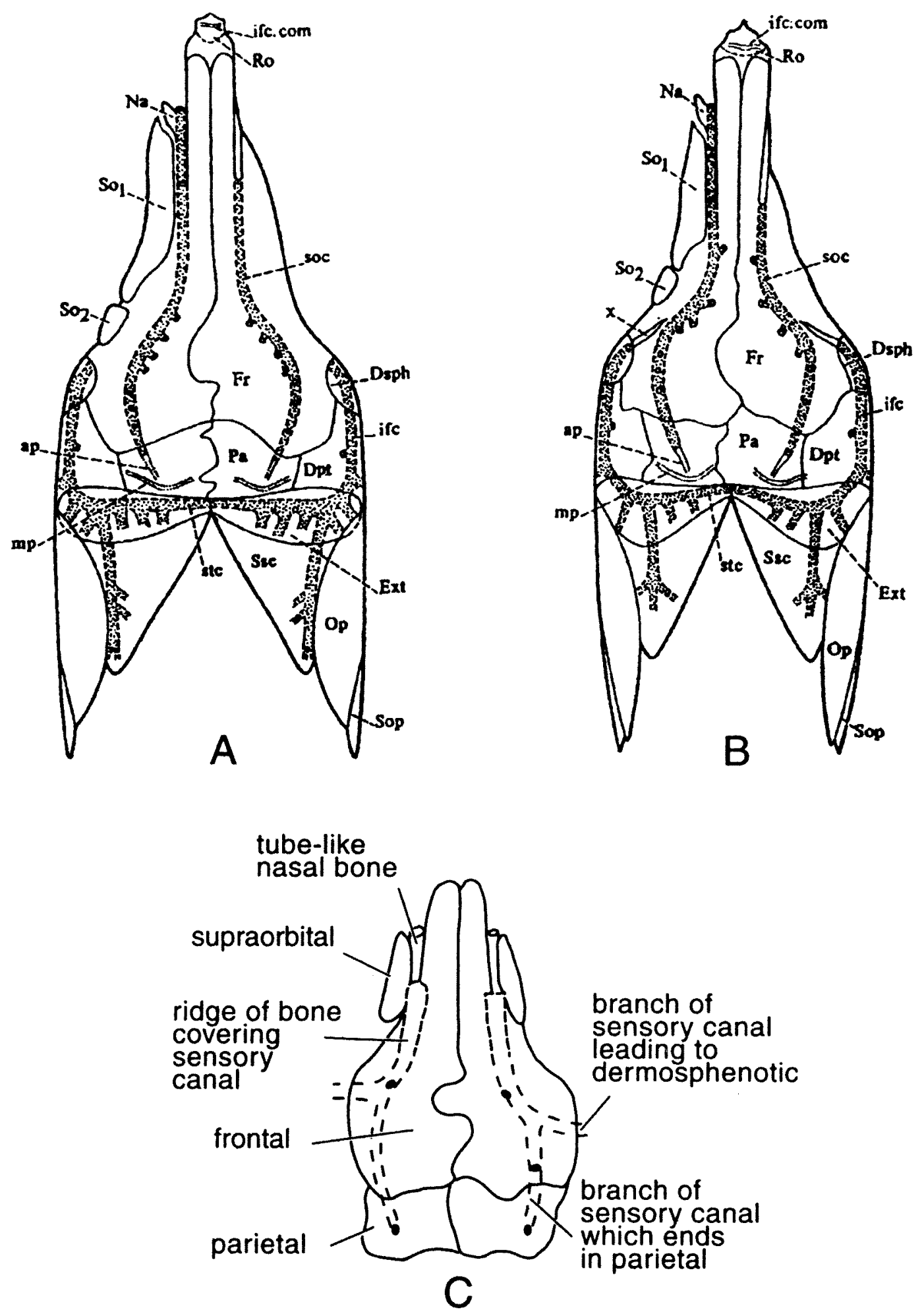

Figure 19 Comparative reconstructions of skull roof. A, Leptolepis coryphaenoides from Nybelin (1974, figure 4B). B, Leptolepis normandica from Nybelin (1974, figure 1B). C, Cavenderichthys talbragarensis, reconstruction based on MMF13564 and MMF36728.

comparison. Neither Woodward (1895) nor Cavender (1970) mention the existence of nasal bones on C. talbragarensis, but they are preserved on several of the studied specimens. The nasal bone provides a protective tube for the sensory canal as it leaves the frontal bone. In C. talbragarensis there is often a quite prominent protective ridge on the frontal, above the supraorbital, covering the sensory canal. When this ridge is destroyed during preservation the canal appears as a deep groove. Just behind this covering ridge is a large pore marking the position of the canal. Beyond this pore the canal curves ventrally, sending a branch onwards towards the parietal. It seems to end at the 

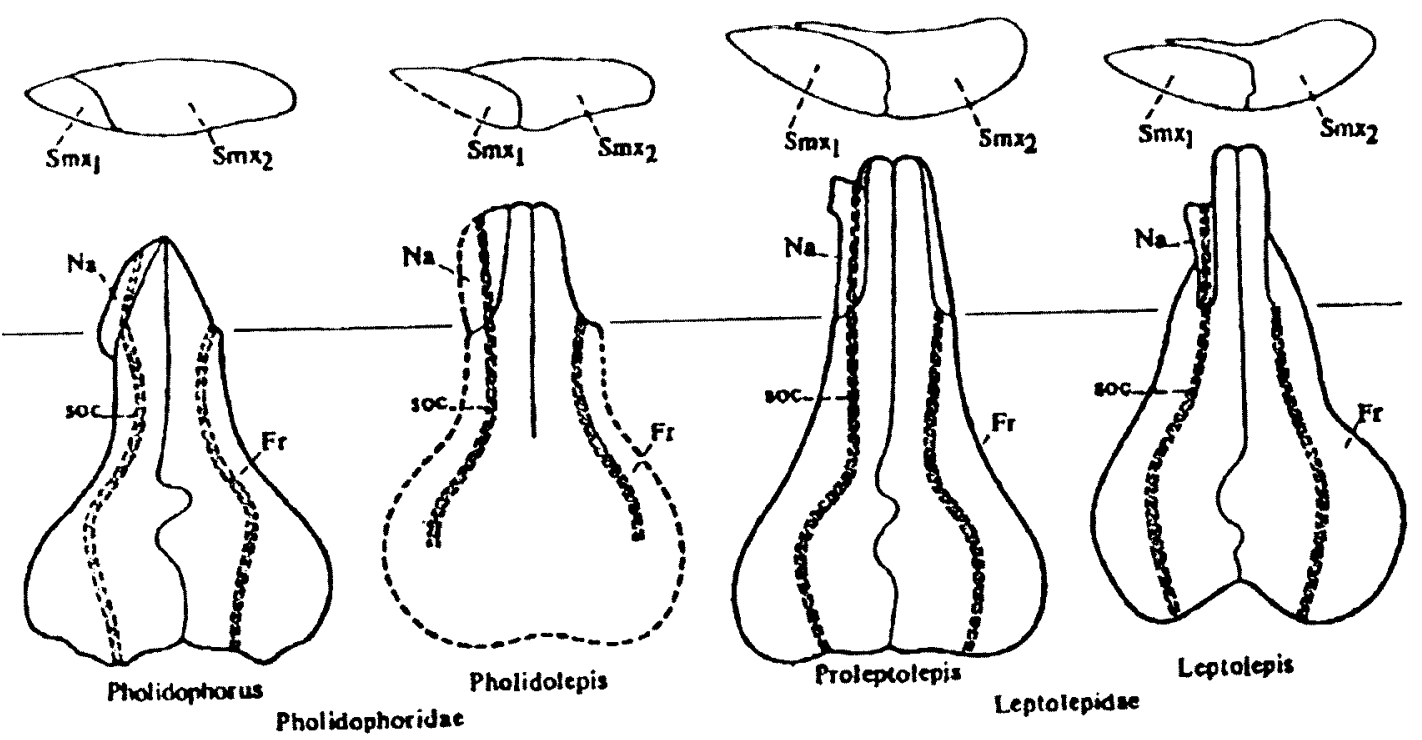

Figure 20 Nybelin (1974, figure 37). Comparison of skull roofs, illustrating the difference between families Pholidophoridae s. str. and Leptolepidae s. str., exemplified by differences in relative size of the two supramaxillae and by the nasal relation to the anterior end of the frontal. This figure shows Nybelin's ideas about evolutionary trends in the form of the skull roof. Cavenderichthys talbragarensis would fit on the right hand end of this series.

back of the parietal where it surfaces through a pore. The branch of the canal heading in a ventral direction passes into the dermosphenotic. Cavender also noted this connection and went on to comment; "This is a significant point of difference in the cephalic sensory system of $C$. talbragarensis, since the junction of the infraorbital and supraorbital canals is known to be absent in Leptolepis (Patterson 1967)." (Cavender 1970: 15)

Another bone of contention is the hyomandibular. Woodward (1895) did not mention it, but Cavender (1970) describes the bone in C. talbragarensis in medial aspect. "The upper portion is expanded into a single broad, articulating head that shows a very slight emargination toward the middle of the dorsal margin. The basal half of the opercular arm is partially differentiated from the expanded portion of the hyomandibular and produces a convex posterior margin. The distal (condylar) part of the opercular arm is not ossified. A large opening is visible near the centre of the expanded portion, which is the foramen for the hyomandibular trunk of the VII nerve. The ventral portion of the hyomandibular is constructed like a slender pillar." (Cavender 1970: 21)

He went on to say that he did not find "an anterior laminar expansion from the upper part of the hyomandibular which contacts the metapterygoid, or an adductor ridge along the postero-lateral margin where it contacts the vertical limb of the preopercule." (Cavender 1970: 21) Basing her diagnosis on her own observations and Cavender's description, Arratia (1997) described a "hyomandibular without preopercular process, but with a well developed levator arcus palatini crest" (Arratia 1997: 19). The latter feature has not been observed by the author. It is found that this bone is generally hidden in $C$. talbragarensis. On seeing the dorso-ventrally flattened specimen (MMF13734a) in the NSW Geological Survey collection it became possible to interpret their descriptions. Nybelin's (1974, figure 3) is very instructive (Figures 9C-E).

It seems clear from these comparisons that $C$. talbragarensis does indeed have a preopercular process on the hyomandibular, that it is not pointed as in the Leptolepis specimens, but that it is obviously serving the same function. The articulation with the preoperculum will cause that bone to be involved when the gill covering is opened. This occurs when the lower jaw is depressed and the opercular series (operculum, suboperculum and interoperculum) are rotated dorsally (Lauder 1982).

The same dorso-ventrally flattened specimen that shows the hyomandibular (MMF13734a) also exposes two complete lower jaws (Figure 21). They can be seen to have a deep, wide dent on the ascending portion of the anterior margin. This dent is not as constricted as the leptolepid notch shown in Nybelin (1974, plate 5, figure 9) for $L$. normandica, but it occurs in the same position. In many of his plates, dentaries are shown that do not exhibit a leptolepid notch, but Nybelin's (1974, plate 14, figure 2), Proleptolepis furcata shows a dentary with a notch in the same place as in $C$. talbragarensis. His description stated "a detached dentary of Proleptolepis sp. shows, however, a rather deep notch in its ascending anterior margin 

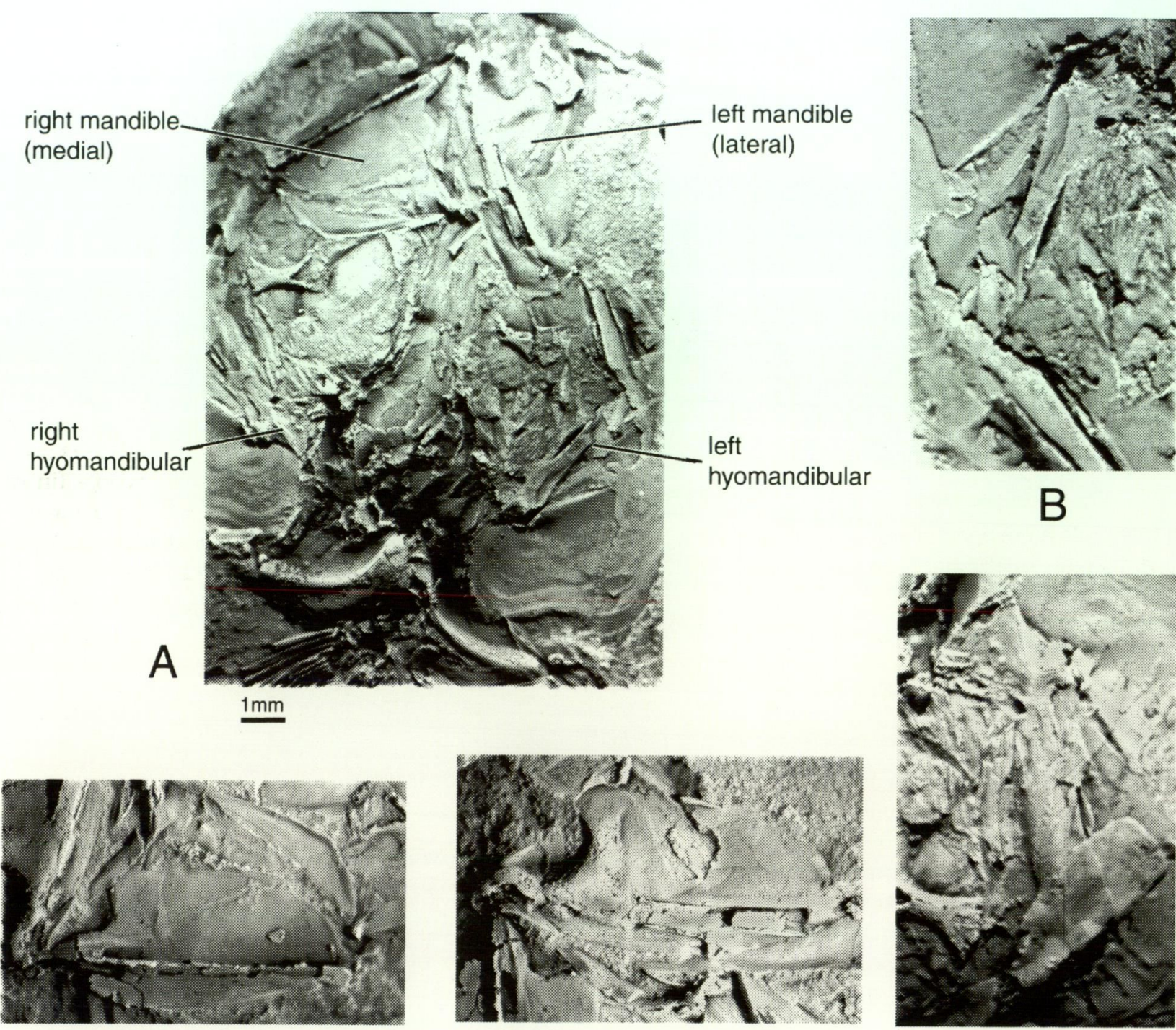

C

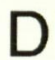

$E$

Figure 21 Cavenderichthys talbragarensis. Dorso-ventrally flattened head of MMF13734a. A, ventral view of flattened head. B, medial view of left hyomandibular. C, medial view of right mandible. D, lateral view of right mandible. E, lateral view of right hyomandibular.

and a similar notch is obviously present in the holotype." (Nybelin 1974). This confirms that the notch in the dentary of $C$. talbragarensis is equivalent to a leptolepid notch.

\section{The Caudal Skeleton}

A caudal reconstruction (Figure 12C) corresponds closely with those of Patterson and Rosen (1977, figures 12A, 12B). The condition of the caudal skeletons of $L$. normandica and $L$. coryphaenoides is not clear, as there were not any well-preserved specimens for Nybelin to describe. However, Patterson and Rosen (1977, figure 22A) figured the caudal skeleton of $L$. coryphaenoides. This shows a caudal fin with three epurals, seven uroneurals, and short neural spines on both preural centra 1 and 2 . It looks more similar to $C$. talbragarensis than the caudal region of Tharsis dubius (Patterson and
Rosen 1977, figure 22B), despite the numbers of bones being the same in T. dubius and $C$. talbragarensis. The other "leptolepid" with a similar caudal arrangement is Leptolepides sprattiformis, with three epurals, five uroneurals, seven hypurals and one urodermals, see Figure 22C.

Patterson was also able to examine some specimens of $C$. talbragarensis kept in the Natural History Museum and comments (Patterson and Rosen 1977: 144) that they only have three epurals, not four as noted by Cavender. He saw six uroneurals arranged as four long strap-like bones and a posterior group of three shorter ones, as well as two urodermals (Figures 12A, 12B).

\section{EVOLUTION}

The rise of the teleosts began in the Triassic but they flourished in the Early Jurassic when they 

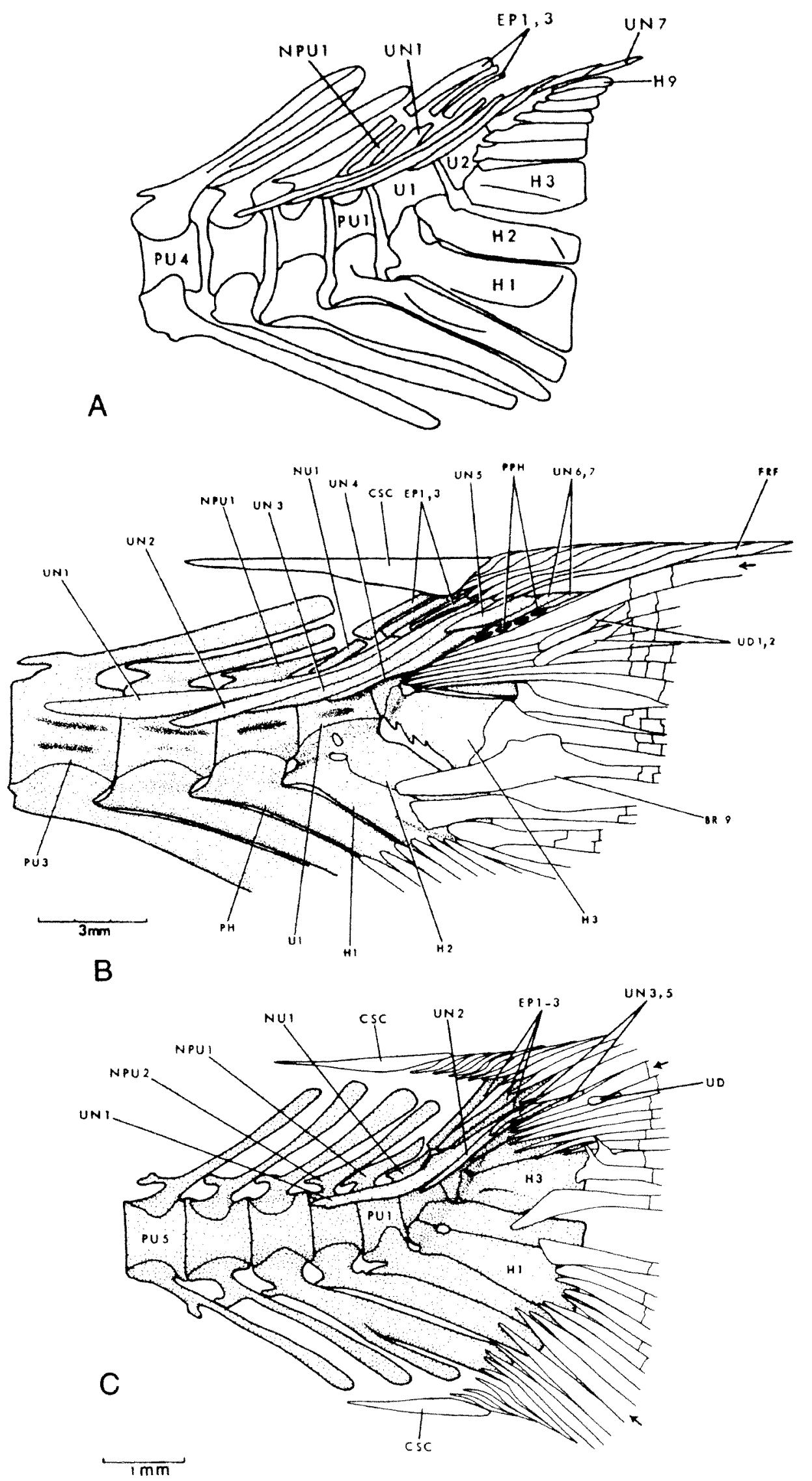

Figure 22 Comparative reconstructions of the caudal skeleton. A, Leptolepis coryphaenoides from Patterson and Rosen (1977, figure 33B), based on BMNH 32456, 32467, P42857 and P7622. B, Tharsis dubius from Patterson and Rosen (1977, figure 35), based on BMNH P.927. C, Leptolepides sprattiformis from Patterson and Rosen (1977, figure 50), based on BMNH $P 926$. 
rapidly achieved a worldwide distribution. Today the Teleostei is the most abundant and diverse group of vertebrate animal (about 29,000 species.). The earliest teleost has been a matter of conjecture over the years, with the leptolepids long being considered one of the oldest representative groups of teleosts. The pholidophorids arose in the Triassic, a group that has more in common with the holosteans than do the leptolepids. Gardiner (1960) described a possible leptolepid from the Upper Triassic of Tanzania, which he called Leptolepis africana. This would have been the oldest leptolepid, except that Nybelin's (1974: 168) re-examination of the specimen led to its inclusion in the genus Pholidolepis, a member of the Pholidophoridae. This family was considered to be more primitive than the Leptolepididae, but it is still a member of the teleosts (Patterson 1982).

The teleosts arose from the holosteans grade group, and replaced them as the dominant actinopterygians during the Jurassic. Some characters that are considered primitive in teleosts by Arratia (1997) include the following: the parietals suturing with each other; dentition on the parasphenoid; the possession of a suborbital bone; the absence of a preopercular process on the hyomandibular; premaxilla being a slightly triangular bone; absence of supramaxillae; position of quadrate-mandibular articulation located below the posterior of the orbit; having a leptolepid notch; having epineural bones but not epipleural bones; having four epurals; having a high number of hypurals e.g., 10; 10 or more principal caudal rays in the lower lobe; ganoid scales.

Cavenderichthys talbragarensis certainly has many of the characteristics of an early teleost. It has a small, mobile premaxilla, which is free from the maxilla. This is an early teleost characteristic (Rosen 1982), as in later teleosts the premaxilla becomes the dominant bone of the upper jaw, bearing all the teeth. The maxilla is hinged in the ethmoid region and swings anteriorly as the mouth opens. This helps to prevent water spilling from the corners of the mouth so encouraging food to be drawn into the mouth. As the mandible is depressed the operculum rises and rotates outwards, also encouraging the through flow of water and food (Lauder 1982).

The roof of the skull has a continuous suture between the frontals and the parietals. This is characteristic of early teleosts (Arratia 1985), but the later trend is for separation of the parietals to allow insertion of muscles. There also seems to be a trend to a reduced number of tubules branching from the sensory canals, certainly within the leptolepids if not within all teleosts. In this respect $C$. talbragarensis shows an advanced feature.

Actinopterygian locomotion involves two styles, firstly caudal propulsion which is used for cruising and sprint swimming, acceleration and fast turns, and secondly median and paired fin propulsion used for slow swimming and in precise manoeuvres (Webb 1982). C. talbragarensis makes use of both these modes of swimming, with an emphasis on caudal propulsion. The well-ossified axial skeleton gives it strength, its homocercal tail outline gives it a balanced force from the caudal area, while the scooped out centre of the tail improves flexibility and steady swimming. The low position of the pectoral fin and the middle position of the pelvic fins are early teleost characteristics (Gosline 1971) as the trend is for the pectoral fins to rise while the pelvic fins become placed in a forward position. The collapsible dorsal fin can reduce drag during fast swimming but can also be raised to act like a keel, especially during tight turns. The light scales have reduced resistance in unsteady swimming, and they help to reduce the mass of the body (Webb 1982).

C. talbragarensis has a primitive location of the pectoral and pelvic fins, and yet the arrangement of the premaxilla and maxilla is one stage advanced from primitive. Rosen (1982) commented, "changes in jaw mechanics first arose, and in some cases proliferated, in teleosts with a primitive fin arrangement and morphology" (Rosen 1982: 269). There is no inherent reason why characters should evolve at the same pace. It is possible that the advanced placement of paired fins did not become a selective advantage until the jaw structure had been modified significantly. The change in feeding style allowed by the more advanced mouth may have been aided by the forward placement of the paired pelvic fins, closer to the centre of gravity of the fish.

Considering Arratia's (1997) list of primitive characters, $C$. talbragarensis has parietals with a suture between them, the quadrate-mandibular articulation appears to be below the middle of the orbit, the leptolepid notch is wide, and it has epineural bones. In these characteristics it is primitive. However, many of its features are more advanced than primitive as it has no dentition on the parasphenoid, does not have a suborbital bone, does possess a preopercular process on the hyomandibular, has two supramaxillae, has epipleural bones, has commonly three epurals, seven or eight hypurals, nine principal rays in the lower lobe of caudal fin, and has cycloid scales.

One of the major advantages of this study over previous work is the large amount of material included, namely approximately 240 specimens. Thus it has been possible to assess the internal variation and whether there is more than one species in the population. The material includes a range of sizes of the specimens and a range of states of preservation, including at least one good example of all the cephalic dermal bones and many 
examples of well-preserved fins and axial skeleton. The major conclusion is that there is only one species of fish originally called Leptolepis by Woodward, not three as he proposed. This is supported by a statistical analysis of the range of dimensions of the specimens. There are certainly other genera present in the population, but they will be described in another paper. The leptolepids represent a population with a preponderance of young individuals, but also with a representative sample of older individuals. Woodward's Leptolepis gregarius is the juvenile form of C. talbragarensis, while $L$. lowei, in which the head appears to be elongated, is an artefact of preservation.

\section{ACKNOWLEDGEMENTS}

I owe a deep debt of gratitude to many people, including the following: Professor K.S.W. Campbell, my supervisor, for his patience and inspiration; Dr R.E. Barwick for teaching me the intricacies of Photoshop and Illustrator; Dr I.S. Williams, RSES, for his expertise and help with the SHRIMP analysis; Dr A. Christy, ANU, for carrying out the EXDA analysis; Dr M.V.H. Wilson, University of Alberta for his very helpful review; Professor R.J. Arculus, ANU, for help with the thin sections; Dr G.C. Young, ANU and Dr R.K. Jones, Australian Museum for access to specimens, Dr G.D. Edgecombe, Australian Museum, for preliminary editing; Dr J.A. Long, Museum Victoria, for help with publication; Dr I.G. Percival, NSW Geological Survey and G. Dargan, NSW Geological Survey for showing me the dorsoventrally flattened specimen.

\section{REFERENCES}

Agassiz, L. (1833-44). Recherches sur les Poissons Fossiles. Neuchatel.

Arratia, G. (1985). Late Jurassic teleosts (Acinopterygii, Pisces) from northern Chile and Cuba. Palaeontographica Abt. A 189: 29-61.

Arratia, G. (1997). Basal teleosts and teleostean phylogeny. Verlag Dr Friedrich Pfeil, Munchen.

Cavender, T. M. (1970). A comparison of Coregonines and other salmonids with the earliest known teleostean fishes. In C. C. W. Lindsey (ed.), Biology of Coregonid Fishes. University of Manitoba Press, Winnipeg

Dulhunty, J. A, and Eadie, J. (1969). Geology of the Talbragar fossil fish bed area. Journal and Proceedings of the Royal Society of New South Wales 102: 1-4.

Etheridge, R. J. and Olliff, A. S. (1890). The Mesozoic and Tertiary insects of New South Wales. Memoirs of the Geological Survey of New South Wales, Palaeontology 7 : 1-12.

Gardiner, B. G. (1960). A revision of certain actinopterygian and coelacanth fishes, chiefly from the Lower Lias. Bulletin of the British Museum of Natural History, Geology 4: 241-384.

Gosline, W. A. (1971). Functional Morphology and Classification of Teleostean Fishes. The University Press of Hawaii, Honolulu.

Hind, M. C. and Helby, R. J. (1969). The Great Artesian Basin in New South Wales. Geology of New South Wales. G. H. Packham. Journal of the Geological Society of Australia. 16, 1: 490.

Lauder, G. V. J. (1980). Evolution of the feeding mechanism in primitive actinopterygian fishes: a functional anatomical analysis of Polypterus, Lepisosteus, and Amia. Journal of Morphology 163 283-317.

Lauder, G. V. J. (1982). Patterns of evolution in the feeding mechanisms of actinopterygian fishes. American Zoology 22: 275-285.

Long, J. (1991). The long history of Australian fossil fishes. In P. Vickers-Rich (ed.), Vertebrate Palaeontology of Australasia pp. 337-428. Monash University Publications, Melbourne.

Norden, C. R. (1961). Comparative osteology of representative salmonid fishes, with particular reference to the grayling (Thymallus arcticus) and its phylogeny. Journal Fisheries Research Board of Canada 18: 679-791.

Nybelin, O. (1974). A revision of the leptolepid fishes. Acta Regiae Societatis Scientiarum et Litterarum Gothoburgensis, Zoologica 9: 1-201.

Patterson, C. (1967). Are the teleosts a polyphyletic group? Colloques Internationaux du Centre National de la Recherche Scientifique 163: 93-109.

Patterson, C. (1977). The contribution of palaeontology to teleostean phylogeny. In M. K. Hecht, P. C. Goody and B. M. Hecht (eds), Major patterns in vertebrate evolution pp. 579-643. Plenum Press, New York.

Patterson, C. (1982). Morphology and interrelationships of primitive actinopterygian fishes. American Zoologist 22: 241-259.

Patterson, C. and Rosen, D. E. (1977). Review of Ichthyodectiform and other Mesozoic teleost fishes and the theory and practice of classifying fossils. Bulletin of the American Museum of Natural History 158: $81-172$.

Percival, 1. G. (1979). The Geological Heritage of New South Wales. Sydney, Australian Heritage Commission, and the Planning and Environment Commission of New South Wales, pp. 237-244.

Pogson, D. J. and Cameron, R. G. (1999). Surat Basin. Explanatory Notes, Dubbo Geological Sheet 1:250 000 S1/55-4, Geological Survey of New South Wales, Mineral Resources of NSW, pp. 330-332.

Rosen, D. E. (1982). Teleostean interrelationships, morphological function and evolutionary inference. American Zoologist 22: 261-273.

Veevers, J. J. (ed.) (2000). Billion-year earth history of Australia and neighbours in Gondwanaland. GEMOC Press, Sydney.

Wade, R. T. (1941). The Jurassic fishes of New South Wales. Journal and Proceedings of the Royal Society of NSW 75: 71-84.

Waldman, M. (1971). Fish from the freshwater lower Cretaceous of Victoria, Australia, with comments on 
the palaeo-environment. Special Papers in Palaeontology. No 9.

Walkom, A. B. (1921). Mesozoic floras of New South Wales. Part 1. Fossil plants from Cockabutta Mountain and Talbragar. Memoirs of the Geological Survey of New South Wales, Palaeontology 12: 1-21.

Webb, P. W. (1982). Locomotion patterns in the evolution of actinopterygian fishes. American Zoology 22: 329 342.

White, M. (1981). Fish beds reveal lush fossil forest. Australian Natural History 20(7): 227-230.

Woodward, A. S. (1895). The Fossil Fishes of the Talbragar Beds (Jurassic?). Memoirs of the Geological Survey of New South Wales, Palaeontology 9: 1-27.

Manuscript received 1 February 2005; accepted 27 July 2005. 